University of Louisville

ThinkIR: The University of Louisville's Institutional Repository

Electronic Theses and Dissertations

$5-2020$

\title{
Oral health-related quality of life in US adults with type 2 diabetes.
}

\author{
Giang Truong Vu \\ University of Louisville
}

Follow this and additional works at: https://ir.library.louisville.edu/etd

Part of the Dental Public Health and Education Commons, Health Services Administration Commons, and the Health Services Research Commons

\section{Recommended Citation}

Vu, Giang Truong, "Oral health-related quality of life in US adults with type 2 diabetes." (2020). Electronic Theses and Dissertations. Paper 3412.

https://doi.org/10.18297/etd/3412

This Doctoral Dissertation is brought to you for free and open access by ThinkIR: The University of Louisville's Institutional Repository. It has been accepted for inclusion in Electronic Theses and Dissertations by an authorized administrator of ThinkIR: The University of Louisville's Institutional Repository. This title appears here courtesy of the author, who has retained all other copyrights. For more information, please contact thinkir@louisville.edu. 
ORAL HEALTH-RELATED QUALITY OF LIFE IN US ADULTS WITH TYPE 2 DIABETES

\author{
By \\ Giang Truong Vu \\ D.D.S, Can Tho University of Medicine and Pharmacy, 2011 \\ M.S., University of Rochester, 2016

\begin{abstract}
A Dissertation
Submitted to the Faculty of the

School of Public Health and Information Sciences

of the University of Louisville

in Partial Fulfillment of the Requirements

for the Degree of
\end{abstract} \\ Doctor of Philosophy in Public Health Sciences \\ Department of Health Management and Systems Sciences \\ University of Louisville \\ Louisville, Kentucky
}

May 2020 
Copyright 2020 by Giang Truong Vu

All rights reserved 



\title{
ORAL HEALTH-RELATED QUALITY OF LIFE
} IN US ADULTS WITH TYPE 2 DIABETES

\author{
By \\ Giang Truong Vu \\ D.D.S, Can Tho University of Medicine and Pharmacy, 2011 \\ M.S., University of Rochester, 2016
}

A Dissertation Approved on

April 1, 2020

By the following Dissertation Committee:

Dissertation Committee Chair

Bert B. Little, Ph.D., M.A.

Robert J. Esterhay, M.D.

J'Aime C. Jennings, Ph.D, M.P.A.

Liza Creel, Ph.D., M.P.H

Lawrence Gettleman, D.M.D., M.S.D. 


\section{DEDICATION}

This dissertation is dedicated to my loving family who always loved, encouraged and supported my desire for knowledge and my pursuit of the American Dreams for a better life for my life throughout my doctoral studies. 


\section{ACKNOWLEDGEMENTS}

I would like to thank my committee chair and advisor, Dr. Bert Little, for his incredible patience, constant encouragement, and continued support during the most challenging times of my doctoral journey. I would also like to thank Dr. Robert Esterhay for his generous support and suggestions. I also want to extend my gratitude to Drs. J'Aime Jennings, Liza Creel, and Lawrence Gettleman for their expertise. Thanks to my parents Tam Vu and Thu-Hong Tang for their unwavering support; to my grandmother Hoa Ly for her encouragement; to my brother An Vu for taking care of my parents when I am away from home so I can focus more on my studies; to my friends Thuy Le and Tram Do for always comforting me during the most difficult times of my life. I would like to thank University of Louisville Graduate School Scholarships, and State University Partnership between School of Public Health and Information Sciences and Medicaid for their scholarships. 


\section{ABSTRACT \\ ORAL HEALTH-RELATED QUALITY OF LIFE}

IN US ADULTS WITH TYPE 2 DIABETES

Giang T. Vu

April 1, 2020

This dissertation focused on the relationship between type 2 diabetes (T2DM) and oral health-related quality of life (OHRQoL) and the factors associated with this relationship in the US. The objectives of the dissertation research were a three-part process: (1) to understand the relationships of T2DM with poor OHRQoL, clarify risk and preventive factors that affect this association, and identify research gaps in the literature, (2) to analyze risk factors associated with poor OHRQoL in US adults with T2DM using a nationally representative random probability cluster sample, and (3) to apply structural equation modeling (SEM) to a simplified Andersen’s Behavioral Model (ABM) to analyze the causal effects of T2DM and other factors on OHRQoL in adults from a nationally representative survey in the US. The first, second, and third objectives were met in Aim 1, Aim 2, and Aim 3, respectively.

In Aim 1, there were 16 empirical articles included the systematic review that examined the association between T2DM and OHRQoL. Half of the reviewed studies did not include a control or comparison group (participants with non-T2DM). All investigations used samples of convenience, or surveys at the community level outside of the US. No studies were conducted at the national level in the US. Five studies included 
used only bivariate analysis and did not control for confounders. The remaining 11 studies used multivariate analysis, but none of them used a theoretical framework to guide their approach. Limited evidence supported the association between T2DM and poor OHRQoL. Some data support analyses that an increased susceptibility to periodontal disease, dry mouth, and dental caries may have negative effects on well-being and quality of life among individuals with T2DM. The findings of Aim 1 highlight the need for further research.

In Aim 2, the 2003-2004 National Health and Nutrition Examination Survey (NHANES) data set was used. The sample included 2,945 participants aged 20 or older sampled with a probability-based cluster design representing 131,397,654 million persons in the US population. Multiple logistic regression was used to predict severity scores (OHIP-ADD) and prevalence scores (OHIP-SC) with the ABM theoretical framework. We found that OHRQoL was poorer among US adults with T2DM, especially those with uncontrolled glycemia. Risk factors for poor OHRQoL included untreated dental caries, periodontal disease, unmet denture needs, obesity, female gender, African American ethnicity, and low income. Higher education, private dental coverage, and annual dental prophylaxis was associated with higher OHRQoL.

In Aim 3, the analysis of a nationally representative sample of 2,798 participants aged 20 or older representing 124,525,899 individuals in the US population was done. We applied SEM to a simplified three-factor Andersen's model to analyze the causal effects of T2DM and other factors on OHRQoL. Causal pathways of the interrelationships of T2DM, need, personal health practices and use of services with OHRQoL were analyzed in a simplified three-factor ABM. Using SEM, T2DM had an 
impact on need, which in turn, had direct and indirect effects on OHRQoL. Need also influenced personal health practices and use of services, which in turn, affected OHRQoL. Education and income also affected personal health practices and use of services.

In summary, a theory-driven, practice-validated conceptual model with rigorous statistical methodology using a nationally representative sample in the US was used to analyze the association and pathways of T2DM and OHRQoL, as well as factors associated with these relationships. The present research indicates that T2DM negatively affected OHRQoL in US adults. Risk factors for poor OHRQoL (in descending order of importance) were current smoking, untreated dental caries, uncontrolled T2DM, unmet denture need, female gender, obesity, African American ethnicity, and periodontal disease. Protective factors from OHRQoL impairment were private dental insurance, college education, and annual dental prophylaxis. Moreover, need directly and indirectly influenced OHRQoL. Personal health practices and use of services also had affected OHRQoL.

Funding Disclosure: This project did not receive any financial support.

Keywords: type 2 diabetes (T2DM); oral health; quality of life; oral health-related quality of life (OHRQoL); United States. 
TABLE OF CONTENTS

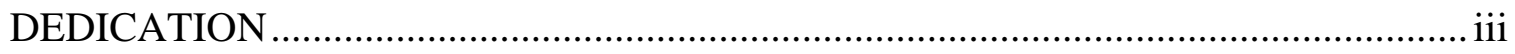

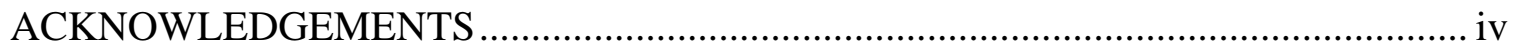

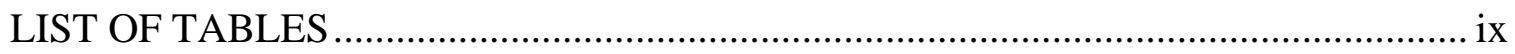

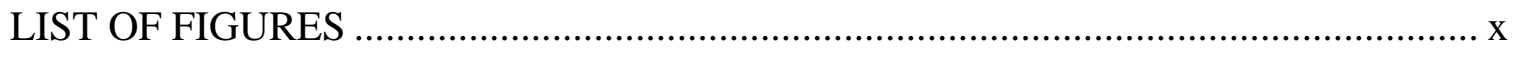

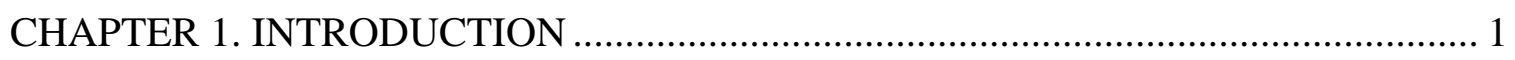

CHAPTER 2. FACTOR ASSOCIATED WITH ORAL HEALTH-RELATED QUALITY

OF LIFE IN ADULTS WITH TYPE 2 DIABETES MELLITUS: A SYSTEMATIC

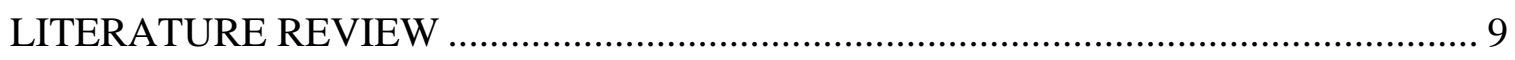

CHAPTER 3. ORAL HEALTH-RELATED QUALITY OF LIFE IN US ADULTS

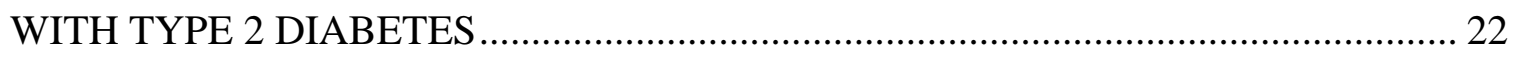

CHAPTER 4. LINKS BETWEEN ORAL HEALTH-RELATED QUALITY OF LIFE IN US ADULTS AND TYPE 2 DIABETES: STRUCTURAL EQUATION MODELING

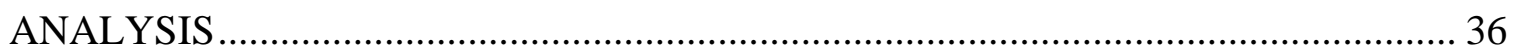

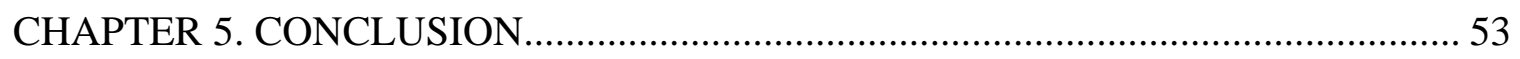

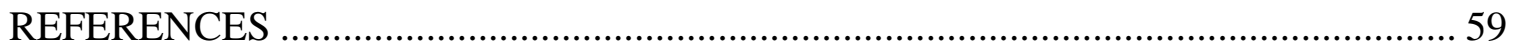

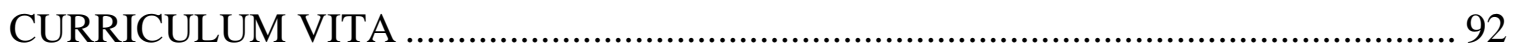




\section{LIST OF TABLES}

Table 2.1. Data extracted from reviewed studies without control group ........................... 65

Table 2.2. Data extracted from reviewed studies with control group ............................... 68

Table 3.1. Demographics and potential risk factors associated with OHRQoL in US adults with and without diabetes according to OHIP-ADD and OHIP-SC cutoff values 71

Table 3.2. Bivariate analysis of participant's characteristics by T2DM status ................ 73

Table 3.3. Distribution of prevalence by item in the weighted sample............................ 76

Table 3.4. Distribution of OHIP scores by domains in the weighted sample .................. 77

Table 3.5. Multivariate analysis of factors associated with poor OHRQoL (measured by

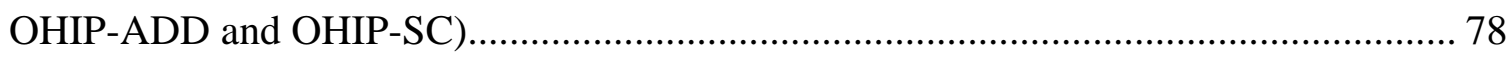

Table 4.1. Characteristics of study variables in the weighted sample.............................. 80

Table 4. 2. Fit indices for the measurement (CFA) and SEM models .............................. 83

Table 4.3. Factor loadings and correlation coefficients in CFA ……............................... 84

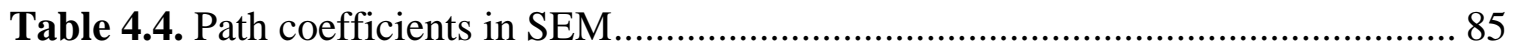

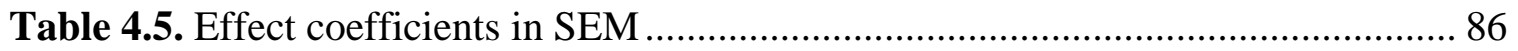




\section{LIST OF FIGURES}

Figure 1.1. Andersen’s Behavioral Model of Health Care Utilization .......................... 87

Figure 2.1. PRISMA flow diagram illustrating the study selection process................... 88

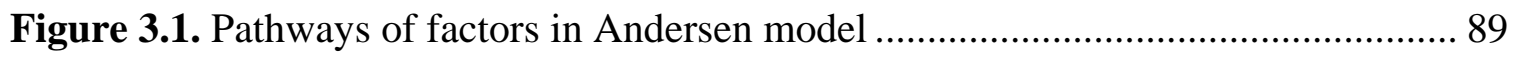

Figure 4.1. DWLS standardized estimates for the confirmatory factor analysis............ 90

Figure 4.2. DWLS standardized estimates for the structural model. ........................... 91 


\section{CHAPTER 1. INTRODUCTION}

\subsection{BACKGROUND}

Globally, 415 million adults have type 2 diabetes mellitus (T2DM), and about 642 million adults are predicted to have T2DM by 2030, according to the International Diabetes Federation (IDF). ${ }^{1}$ In the US, $34.5 \%$ of all US adults had prediabetes, and $15.3 \%$ of adults with prediabetes was told by a health professional that they had T2DM according to the 2020 National Diabetes Statistics Report. ${ }^{2}$ More importantly, 13\% of all US adults had diabetes, and approximately $90-95 \%$ of people with diabetes have T2DM. ${ }^{2}$ This metabolic disorder is a chronic disease characterized by hyperglycemia and the result of a combination of resistance to insulin, inadequate insulin secretion, and excessive or inappropriate glucagon secretion. T2DM is associated with family history, sedentary lifestyle, excessive body weight, stress, and poor eating habits.,

In the US, the prevalence of untreated dental caries in adults decreased in the age groups $20-44,45-65$, and $>65$ years old with $31.6 \%$, 27.5\%, and $22.7 \%$ untreated cavities, respectively. ${ }^{5}$ In contrast, the prevalence of periodontitis disease increased with age, which was $47.2 \%$ and $70.1 \%$ adults aged 30 to 64 years and adults 65 years or older, respectively. ${ }^{5}$ The prevalence of total tooth loss (edentulism) was 3.8\% and $27.3 \%$ in adults aged 30-64 years, and adults 65 years or older, respectively. ${ }^{5}$ Adults 20-64 years had an average of 24.9 remaining teeth while elderly had an average of 18.9 remaining teeth. $^{5}$ 
Chronic hyperglycemia associated with T2DM, if left untreated, can lead to serious complications in both general (medical) health and oral health. ${ }^{3,4}$ Specifically, T2DM may cause short-term and long-term adverse events such as diabetic nephropathy, neuropathy, retinopathy, atherosclerosis, peripheral artery disease, diabetic heart disease and cardiomyopathy. ${ }^{6}$ In addition, T2DM individuals with hyperglycemia also have poor oral healing processes when they have mucous membrane injuries, which may be the result of hyposalivation, salivary chemical composition changes, decreased immune function, or diet changes. ${ }^{7,8}$ Such changes may lead to an increased prevalence of oral pathology along with increased accumulation of plaque, calculi, and higher frequency of oral infections. ${ }^{4,9}$ In addition, poorly controlled T2DM has been shown to be associated with periodontal disease. ${ }^{10}$ Dental caries are reported to be more common and more severe in T2DM patients. ${ }^{4}$ Periodontal diseases and dental caries, major causes of tooth loss along, with poorly fitted dentures negatively affect eating habits, restrict food choice, and contribute to nutritional imbalance and lowering quality of life. ${ }^{3,10}$

In addition to clinical effects of oral conditions, it is important to consider the effects of the self-perception of an individual on well-being and how self-perception impacts an individual's self evaluation of physical, psychological, and social functioning. ${ }^{10,11}$ The new definition of oral health by the World Health Organization (WHO) states that oral health is a state of being free from oral diseases not only in terms of physical effects, but also the effects on psychosocial well-being. ${ }^{12}$ This paradigm shift indicates a change from focusing solely on the clinical impacts of disease to a broader view that considers one's self-perception of the impact of dental conditions on individual well-being, and valuation of oral impact on physical, psychological, and social quality of 
life. ${ }^{10}$ Part of the paradigm shift is measurement of oral health-related quality of life (OHRQoL). It is a self-perceived assessment of an individual regarding the effect of oral diseases on quality of life's physical, psychological, and social functioning. ${ }^{10,13}$

Medical complications of T2DM were well studied, but effects on oral health and OHRQoL were less well documented. Prevalence of oral pathology was increased in people with T2DM., ${ }^{3,4}$ Specifically, a number of empirical studies have shown a higher prevalence of periodontal diseases, dental caries, and dry mouth in individuals with T2DM compared to non-T2DM individuals. Previous studies have used different instruments in different language versions with variable numbers of questionnaire items, resulting in inconsistent measurement of OHRQoL among populations. ${ }^{14,15}$ Some studies reported that oral disorders contribute to reduced ability to function and to lower quality of life in people with T2DM. ${ }^{10,11}$ Other studies have failed to find differences between T2DM and non-T2DM in OHRQoL. ${ }^{16-18}$

Collectively, there is inconsistency in the empirical literature regarding the association between T2DM and OHRQoL, resulting in limitations of understanding of risk and protective factors associated with this relationship. However, evidence-based investigations studies consistently link oral pathologies and T2DM with poor general medical health outcomes. ${ }^{3,4}$

\subsection{RESEARCH AIMS}

The objectives of the dissertation research were three fold: (1) to understand the relationship of T2DM with poor OHRQoL, clarify risk and preventive factors that affect this association, and identify research gaps in the literature, (2) to analyze risk factors associated with poor OHRQoL in US adults with T2DM using a nationally representative 
probability cluster random sample, and (3) to apply SEM to a simplified Andersen Behavioral Model (ABM) to analyze the causal effects of T2DM and other factors on OHRQoL in adults from a nationally representative survey in the US.

The dissertation study was designed such that each aim informed the subsequent aim. A three-pronged approach was applied to collectively explain and predict (a) the association and the effects of T2DM on OHRQoL and (b) the risk and protective factors of OHRQoL in US adults with T2DM. In Aim 1, a systematic literature review was conducted to establish the need for this dissertation's research, which is to examine the relationships of T2DM with OHRQoL and factors associated with these relationships. In Aim 2, bivariate and multivariate analyses were used to empirically investigate the association between T2DM and OHRQoL and factors influencing this association. In Aim 3, SEM was applied to a simplified three-factor ABM to analyze the causal pathways of T2DM with OHRQoL (perceived oral health outcomes) and other ABM factors.

It is important to note that the 2003-2004 National Health and Nutrition Examination Survey (NHANES) data and the ABM model were used as theoretical framework for Chapter 3 and Chapter 4. However, these two chapters used different variables, resulting in slightly different sample sizes due to missing values. In Chapter 3, the ABM was used as a conceptual model to guide variable selection, and a simplified three-factor ABM was applied as a theoretical framework for SEM in Chapter 4.

\subsection{THEORETICAL FRAMEWORK}

OHRQoL is a complex and relatively new concept that requires a multiple-lens theoretical basis for study. In addition, it is critical to understand the ABM theoretical 
framework used to examine the relationships between T2DM and OHRQoL and factors affecting their relationships.

\subsubsection{Conceptual definitions of OHRQoL}

"Oral health" and "quality of life" are included in the definition of OHRQoL. WHO defines oral health as a state of being free from oral conditions (e.g., chronic mouth and facial pain, oral and throat cancer, oral infection and sores, periodontal disease, tooth decay, tooth loss, oral and throat cancer) that limit people's ability of physical functions (e.g., biting, chewing, smiling, speaking), and psychosocial wellbeing. ${ }^{12}$ In the report of "Oral Health in America," oral diseases were classified into six major categories: (i) mucosal disorders, (ii) developmental disorders, (iii) dental and periodontal infections, (iv) oral and pharyngeal cancers, (v) injuries, and (vi) certain chronic and disabling conditions including oral pain. ${ }^{19}$ Second, quality of life (QoL) is defined as an individual's perception of quality of life in the one's culture and value systems, and in relation to his or her expectations, goals, and concerns. ${ }^{20}$ Health and disease contribute to QoL, defined in levels of physical, psychological, and social functioning. ${ }^{20}$ QoL also includes self perception of life satisfaction, fitness, wellbeing, and health. ${ }^{20}$ The impact of disease and health on QoL is measured by health-related quality of life (HRQoL), a broader concept of QoL. ${ }^{19,20}$

The term OHRQoL is a subset of HRQoL without strict definition. ${ }^{13,21}$

OHRQoL is defined as a multidimensional concept. ${ }^{14}$ The US Surgeon General's report on oral health defined OHRQoL as a multidimensional construct that reflects a person's comfort when eating, sleeping, and engaging in social interaction. ${ }^{19}$ OHRQoL is the interaction between oral conditions and health (general and dental) with social factors. ${ }^{13}$ 
This definition includes one's self-esteem, and satisfaction with respect to oral. ${ }^{19}$ OHRQoL is rigorously defined concept for research purposes in which OHRQoL assesses how oral health affects quality of life in terms of (i) physical functioning (e.g. pain or discomfort when chewing, biting, swallowing, speaking), (ii) psychological functioning (e.g., self assessment of a person's satisfaction, appearance of smile and teeth), and (iii) social functioning (e.g., the level of comfort when speaking and eating in the front of other people). ${ }^{22}$ This definition is more operational because it links to specific and measurable indicators of self perception. ${ }^{14}$

Instruments used to measure OHRQoL vary in the number and format of questions (items) and their responses. ${ }^{14}$ The OHRQoL instrument can include only one question as known as global self-ratings (or single-item ratings). ${ }^{23}$ For example, the question can be "How do you rate your oral health today?” and the response can be in a categorical (from excellent to poor) or visual analog pain scale (100-mm VAS)

format. ${ }^{14,23}$ Multiple-item questionnaires are the most popular method used to measure OHRQoL. ${ }^{14}$ At the First International Conference on Measuring Oral Health, ten OHRQoL instruments were tested for psychometric properties (e.g., reliability, validity, and responsiveness) were presented that include (i) Oral Health Impact Profile (OHIP), (ii) General Oral Health Assessment Index (GOHAI), (iii) RAND Dental Health Index (SF-36), (iv) Oral health quality of life (OHQoL), (v) Social Dental Scale, (vi) Dental Impact Profile, (vii) Subjective Oral Health Status Indicators, (viii) Dental Impact on Daily Living, (ix) Oral-health related quality of life, (x) Oral Impact on Daily Performance (ODIP). ${ }^{14,15,24}$

\subsubsection{Oral Health Impact Profile}


The OHIP is a widely used instrument to measure OHRQoL ${ }^{14,15}$ developed by Slade and Spencer based on Locker's adaption of the WHO's new definition of oral health. ${ }^{10,13}$ The OHIP questionnaire can have different numbers of items. For example, it can have 49 items for the full version (OHIP-49), 20 items for the OHIP-20, 14 items for the short version (OHIP-14), seven items for the OHIP-NHANES version, and five items for the ultra-short version (OHIP-5). ${ }^{14,15}$ The OHIP assesses seven dimensions of oral conditions’ impact on people’s OHRQoL including functional limitation (e.g., trouble pronouncing some words, worsened taste), physical pain (e.g., painful aches, uncomfortable eating food), physical disability (e.g., unsatisfactory diet, interruption of meals), psychological discomfort (e.g., self-conscious, tense feeling), psychological disability (e.g., difficult to relax, feeling embarrassed), social disability (e.g., been a bit irritable, difficult doing usual jobs), and handicap (e.g., less satisfying life, totally unable to function). ${ }^{25,26}$ The NHANES version (known as OHIP-NHANES) was developed as the shorter version of the OHIP. ${ }^{27}$ This seven-item questionnaire was designed to assess seven dimensions of OHRQoL. Each item describes a specific impact of oral conditions on quality of life. ${ }^{27}$ Participants were asked "how frequently they experience the impact over the preceding year”27 on a five-point ordinal scale (i.e., never, hardly ever, occasionally, fairly often, very often). ${ }^{27}$

\subsubsection{Andersen Behavioral Model}

$\mathrm{ABM}$ is one of the most well-known conceptual models used in the analysis

of health services and key health outcomes (Figure 1.1). ${ }^{28}$ It provides a framework for the analysis of factors that influence utilization of health services and key health outcomes. The model was originally developed in 1968 and revised in 1995 by Andersen to analyze 
social, individual, and contextual factors that influence health services use. ${ }^{28,29}$ The model analyzes the difference in use of health services between individuals, and explains used of services by five factors: (i) predisposing, (ii) enabling resources, (iii) need, (iv) personal health practices and use of services, (v) health outcomes. ${ }^{29,30}$ Predisposing factors include demographic characteristics (e.g., age, sex, race/ethnicity) that exist prior "health outcomes.”29 Enabling resources are financial and organizational factors that enable services utilization (e.g., health insurance, education, cost of care). ${ }^{29}$ Need factors are perceived and clinician-evaluated need for health care treatment. ${ }^{29}$ Some individuals may be more predisposed to seek healthcare services, and there are enabling resources that allow them to do so. ${ }^{30}$ However, even when predisposing and enabling factors present, health services use will only occur if an individual perceives a need for treatment or the individual is evaluated by a clinical for treatment need. ${ }^{29,30}$ The interrelationship between these three contextual factor categories will, in turn, determine the likelihood of personal health practices (e.g., smoking) and use of services (e.g., frequency of annual dental prophylaxis, reason of dental visit, dental visit frequency). ${ }^{30}$ In addition, the ABM and the Baker et al study ${ }^{30}$ suggest that personal health practices and use of services will influence health outcomes (both perceived and evaluated health status) and personal satisfaction with care. 
CHAPTER 2. FACTOR ASSOCIATED WITH ORAL HEALTH-RELATED QUALITY

OF LIFE IN ADULTS WITH TYPE 2 DIABETES MELLITUS: A SYSTEMATIC

\author{
LITERATURE REVIEW
}

\title{
$2.1 \quad$ INTRODUCTION
}

Type 2 diabetes mellitus (T2DM), a metabolic disorder with a multifactor etiology, is a major chronic disease that is an epidemic worldwide. T2DM is associated with family history, sedentary lifestyle, excessive body weight, stress and poor eating habits, and characterized by chronic hyperglycemia. ${ }^{1}$ The International Diabetes Federation (IDF) estimated that 415 million adults have diabetes mellitus, and about 642 million adults are predicted to be diagnosed by 2040, globally. ${ }^{1}$ According to the 2020 National Diabetes Statistics Report, 13\% of US adults had diabetes. ${ }^{2}$ T2DM is the most common type of diabetes, affecting $90-95 \%$ of people with diabetes. ${ }^{1,2}$ If left untreated, chronic hyperglycemia associated with T2DM can cause serious short-term and longterm adverse events on both general (medical) health (e.g., diabetic nephropathy, neuropathy, retinopathy, atherosclerosis, peripheral artery disease/amputation, cardiomyopathy) and oral health (e.g., periodontitis, dental caries, xerostomia, edentulous, soft tissue lesions). ${ }^{17}$ Medical complications of T2DM are well documented, but effects on oral health are less well studied. ${ }^{3}$

The World Health Organization (WHO) defines oral health as "a state of being free from mouth and facial pain, throat and oral cancer, tooth loss, tooth decay, oral 
infection, and sores, periodontal (gum) disease, and other disorders that limit an individual's capacity in biting, chewing, smiling, speaking, and psychological wellbeing." ${ }^{\prime 2}$ A paradigm shift from focusing solely on the clinical impacts of disease to a broader view that considers one's self-perception of the impact of dental conditions on individual well-being, and valuation of oral health impact on physical, psychological, and social quality of life is necessary. ${ }^{31}$

Oral health-related quality of life (OHRQoL) is captured in a recently adapted approach to measuring the impact of oral conditions on quality of life. ${ }^{10}$ Several scales have been used to measure OHRQoL, including Oral Health Impact Profile (OHIP), General Oral Health Assessment Index (GOHAI), Oral Impact on Daily Performance (OIDP), the 36-Item Short Form Health Survey (SF-36), ${ }^{11}$ the UK Oral Health related Quality of Life (OHQoL-UK), ${ }^{32}$ and Fatigue in Older Adults (FACIT-F) ${ }^{33}$ Previous studies have used these instruments in different language versions with variable numbers of questionnaire items, sometimes resulting in inconsistent measurement of OHRQoL among populations. ${ }^{9,10,16-18,32,34}$

According to several studies, T2DM may be associated with poorer oral health outcomes, as a number of empirical studies have shown a higher prevalence of periodontal diseases, dental caries, and dry mouth compared to non-T2DM individuals. ${ }^{6,831,35,36}$ In another study, an increased prevalence of oral pathology was found in people with T2DM. ${ }^{17}$ Oral disorders are known to contribute to reduced ability to function and to lower quality of life in people with T2DM. ${ }^{31}$ Other studies have failed to find differences between T2DM and non-T2DM in OHRQoL. ${ }^{8,18}$

Collectively, the current empirical literature is inconclusive regarding the 
association between T2DM and OHRQoL. Indeed, the limited literature on the association between T2DM and OHRQoL is not definitive. In contrast, evidence-based investigations consistently link oral pathologies and T2DM with poor general medical health outcomes (e.g., heart disease, dementia, respiratory infections). ${ }^{10,17}$ Better understanding of predictors of and risk factors for OHRQoL in people with T2DM are important to improve population health. In the present study, prior research on the association between T2DM and OHRQoL is critically assessed. The aim was to produce an understanding of the relationship of T2DM with poor OHRQoL and to clarify risk and preventive factors that affect this association.

\subsection{METHODS}

The Preferred Reporting Items for Systematic Reviews and Meta-Analyses (PRISMA) guidelines were followed in this literature review. ${ }^{37}$

\subsubsection{Review questions}

Is T2DM associated with OHRQoL in adults? If they are associated, what are covariate factors that affect the association of T2DM and OHRQoL?

\subsubsection{Search strategy}

The search terms and phrases were developed to electronically identify relevant articles that reported on OHRQoL in adults with T2DM. The search terms/phrases and Boolean algebra used were: (“oral health-related quality of life” or "OHRQoL” OR (“oral health” AND “quality of life”)) AND (“type 2 diabetes mellitus” OR “T2DM” OR

“diabetes”). Search terms/phrases were systematically used to query the following electronic databases: MEDLINE (via PubMed.gov) and EMBASE (via OVID). The last updated search was performed on February 18, 2020. Year of publication was not 
restricted. Reference lists of the included publications were screened manually, and a “grey literature” (materials and research produced by organizations outside of the traditional commercial or academic publishing and distribution channels) search was conducted to identify any potentially relevant documents such as questionnaires of OHRQoL instruments, instruction, and other relevant print materials.

\subsubsection{Eligible criteria}

The following criteria were used to identify studies eligible for this systematic review: (a) any study design (randomized controlled trials, cross-sectional, case-control, cohort, or pilot); (b) studies that investigated OHRQoL with validated instruments; (c) impact of oral conditions (e.g., presence of dental caries, periodontal disease, tooth loss, oro-facial problems by a clinical examination or self-report) on quality of life; (d) adult study participants with T2DM or diabetes (when not clearly defined as type 1 or type 2). Exclusion criteria were: (a) editorial, letter to the editor, reviews, conference abstracts, and case reports, (b) non-English articles and (c) qualitative studies.

\subsubsection{Study selection and data extraction}

Full text copies of potentially eligible studies meeting the criteria were obtained and reviewed. Data were extracted from the selected articles using piloted PRISMA forms. Critical appraisal and verification were conducted to asses the quality of studies included in the systematic review process. Extracted data were summarized into Table 2.1 (studies without control group) and Table 2.2 (studies with control group) that included year of publication, authors, study design, statistical analysis, sample size, age range, OHRQoL instruments, diabetes diagnosis, and key findings (i.e., perceived and evaluated needs of dental treatment, etc.). In case of disagreements between authors, 
consensus was reached through discussion.

\section{$2.3 \quad$ RESULTS}

\subsubsection{Literature identified}

The PRISMA Flow search protocol for process of screening and articles selection was followed (Figure 1). The initial search yielded 426 unique and potentially relevant articles (MEDLINE via PubMed: 195, EMBASE via OVID: 231). An additional 27 print material documents were identified through other resources (“grey search”). After removing 136 duplicates, 317 unique articles remained for the title and abstract screening. Among the remaining 317 publications, 129 met exclusion criteria for duplication. A total of 188 full-text articles were eligible for the review, of which 172 failed to meet the inclusion criteria (e.g., adult participants with T2DM or diabetes, validated OHRQoL instruments). Ultimately, sixteen articles were included in the systemic review.

\subsubsection{Study and participant characteristics}

Studies selected for inclusion were summarized in Table 2.1 (studies without control group) and Table 2.2 (studies with control group). The earliest included article was published in 2003, and the most recent in 2019. The included studies were from South America (6), Asia (5), Europe (3), and Africa (2).

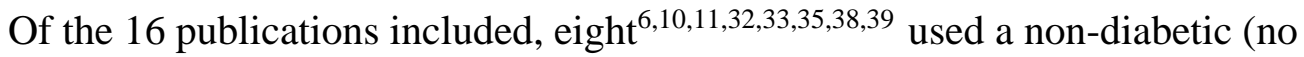
T2DM/diabetes) control group for comparison. The remaining eight studies included a cohort of participants with T2DM or diabetes but did not include a comparison group. Study sample sizes ranged from smallest $(\mathrm{N}=103)$ to largest $(\mathrm{N}=1,400)$ (Tables 2.1 and

2.2). Ages of study participants ranged from 18 to 80 years, with average ages that 
ranged from 43.5 to 64.9 years, where these details were reported. Sample sizes of three studies $^{6,31,36}(\mathrm{~N}=300$ to $\mathrm{N}=1,400)$ were population-based for a state/province/district.

Four studies ${ }^{11,33,38,39}$ were matched case- control (i.e., matched on age and gender) studies with sample sizes of $204,{ }^{11} 447,,^{39} 457,{ }^{38}$ and $500 .{ }^{33}$ Ten studies ${ }^{7-10,17,18,31,34}$ had crosssectional data with sample sizes ranging from $\mathrm{N}=101$ to $\mathrm{N}=350$. Only one study ${ }^{32}$ used a longitudinal sample $(\mathrm{N}=105)$ that analyzed the effect of essential oil mouthwash treatment over three months. All investigations used samples of convenience, or surveys at the community level. No studies were conducted at the national level. Five

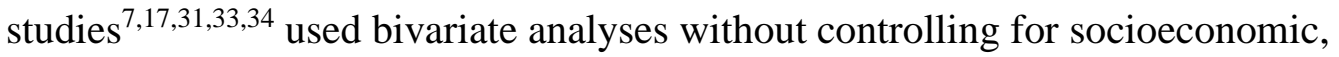
demographic, or other confounding factors. Remaining studies used several different statistical methods that allow adjustment for multiple potentially confounding factors: Poisson regression ( $\mathrm{N}=2$ studies), ${ }^{6,8}$ linear regression $(\mathrm{N}=2),{ }^{11,32}$ and logistic regression $(\mathrm{N}=7){ }^{9,10,18,31,36,38,39}$

\subsubsection{Measurement of OHRQoL}

Researchers used a variety of instruments to measure OHRQoL, including OHIP, GOHAI, OIDP, OHQoL-UK, SF-36, and FACIT-F. Specifically, eight studies ${ }^{6-8,18,31,34,36}$ used OHIP, one ${ }^{10}$ used GOHAI, two ${ }^{9,17}$ used both OHIP and GOHAI, two ${ }^{38,39}$ used OIDP. The three remaining studies used SF-36, ${ }^{11}$ OHQoL-UK, ${ }^{32}$ and FACIT-F. ${ }^{33}$ Of studies that used OHIP, the majority $6,8,9,17,31,34,36,39(\mathrm{~N}=9)$ used the 14-item questionnaire, only two ${ }^{2,7}$ used the 20-item questionnaire. Most investigators ( $\mathrm{N}=7$ ) used OHIP-SC in which the frequency of negative effects or prevalence was calculated by simply counting responses of "fairly often" and "very often." Two investigators used the OHIP-ADD in which severity of the negative impacts was calculated by summing scores of each 
response, with higher scores denoting most severe negative effects. ${ }^{8,34}$ Two studies reported GOHAI scores, which can be a continuous (GOHAI-ADD) or binary variable (GOHAI-SC). ${ }^{9}$

\subsubsection{Factors associated with OHRQoL}

\subsubsection{T2DM}

Among the studies included in this systematic review, three ${ }^{6-8}$ did not distinguish between type 1 (T1D) and type 2 diabetes. The diagnosis of diabetic status included T2DM/ diabetes was established using self-report, clinical evaluations by physicians using laboratory tests (fasting blood glucose $\geq 126$ or glycated hemoglobin $>6.5 \%$ ). Notably, NHANES surveys rely solely on self-reported diabetes diagnosis and type of diabetes. Diabetes status may be dichotomized into yes/no or type 1/type 2. ${ }^{6-8,10,31}$ T2DM status was further categorized into controlled and uncontrolled groups by using different Hb1Ac cut-off thresholds (e.g., 7.5\%, 8\%)..$^{7,11,17,33,38}$ A study that used multivariate adjustment for confounders in a study of French participants reported that those with T1D had lower OHRQoL than those with T2DM. ${ }^{6}$ No association between decreased OHRQoL and T2DM was found in two studies. ${ }^{11,18}$ However, longer time since T2DM diagnosis was associated with a significantly lower OHRQoL for physical functioning, social functioning, and general health. ${ }^{11,18}$ One study, ${ }^{33}$ using simple bivariate analysis, reported significant associations between T2DM and OHRQoL as well as dimensions of OHRQoL but did not control for potential confounders. In another study ${ }^{17}$ investigators reported that poorly controlled T2DM (HbA1c > 8\%) significantly negatively affected chewing, swallowing, speaking, and eating, but it was an uncontrolled bivariate analysis that was possibly confounded. 


\subsubsection{Oral conditions}

Poor oral health (at least one missing tooth that was not replaced, bleeding during brushing, having abscess within the past 12 months) was associated with lower OHRQoL among participants with T2DM. ${ }^{10}$ Dry mouth and wearing removable dentures were statistically significant indicators of poor OHRQoL among participants with T2DM. ${ }^{10}$ Three studies found that periodontitis and dentate status were significantly correlated with lower OHRQoL in bivariate analysis. ${ }^{7,33,38}$

Four studies did not find a significant association between T2DM/diabetes status and OHRQoL using multivariate analysis to adjust for confounding. However, the investigators reported significant associations of lower OHRQoL and periodontal disease and dental caries among T2DM patients. ${ }^{6,832,36} \mathrm{~A}$ higher visual plaque index and fewer teeth were associated poor OHRQoL among participants with T2DM who had chronic periodontitis. ${ }^{31}$ In addition, dry mouth and need for dentures were also significantly associated with lower OHRQoL among participants with T2DM. ${ }^{9,36}$

\subsubsection{Use and behavior factors}

In three studies no association was found between T2DM and OHRQoL, but the researchers found that current smoking, lack of knowledge of oral complications, infrequent brushing, and dental referral by physicians were significant indicators of low OHRQoL among participants with T2DM.8,18,39 In one study, low OHRQoL was correlated with low frequency of dental visits and lack of knowledge of oral conditions (e.g., periodontitis) and poor existing general medical health conditions (e.g., heart, eye, or kidney disease) were correlated with poor OHRQoL. ${ }^{7}$

\subsubsection{Demographics}


Adjusting for potential confounders by multivariate analysis, college education, female gender, and age were significant predictors of lower OHRQoL in participants with T2DM in three studies, ${ }^{6,18,35}$ but OHRQoL was not significantly associated with T2DM.

\subsection{DISCUSSION}

Oral health is an important indicator of general health and well-being. ${ }^{3}$ Dental health and its effect on quality of life for adults with T2DM has been neglected, perhaps because of a focus on other T2DM-related needs. Lack of research on the effects of T2DM, and inconsistencies in that research which does exist, on oral health is also related to this omission in clinical practice. ${ }^{3}$ A large body of evidence indicates that poor oral health may cause systemic medical conditions. ${ }^{3,4}$ Therefore, strong theoretical grounds exist for predicting poorer medical health in adults with T2DM who also have poor dental health. ${ }^{3}$ It is critical to understand how T2DM affects OHRQoL, and how poorly controlled T2DM affects oral health and OHRQoL. This systematic review provides an integration of empirical studies on OHRQoL in adults with T2DM.

The findings of this systematic review show that one of the main reasons for prior discrepancies in the literature is the use of a very broad range of clinical, personal oral health practices, and socioeconomic indicators across different studies. In the present review, a distinction was made between four specific categories for study variables: (a) T2DM, (b) oral conditions, (c) use and behavior factors, and (d) demographics. Using this refined approach, it is shown that current literature provides only very limited evidence that OHRQoL is likely to be associated with T2DM. However, suggestive evidence indicates that adults with periodontal disease have a low OHRQoL associated with T2DM. Collectively, findings of this review also show moderate evidence for an 
increased susceptibility to dental caries, denture need or tooth loss, and dry mouth among those with T2DM. Limited evidence suggests that personal health practices (e.g., infrequent tooth brushing, smoking, infrequent dental visits) and demographics (e.g., education less than college, female gender, low income) may be risk factors for poor OHRQoL among adults with T2DM. Targeted treatments and specific policies aimed at improving oral health for vulnerable populations, especially for those with T2DM, may be developed using these key findings. These data point to the need for oral health assessments among people with T2DM, and necessity of vigilant, prompt attention to signs of potential oral complications in this vulnerable population with appropriate interventions. Patient health education, especially for those with T2DM, will help individuals be aware of signs and symptoms of poor oral health and identify conditions for which they should urgently seek dental care.

Strong theoretical and biological reasons exist for predicting that individuals with T2DM will be particularly susceptible to a wide range of oral health problems and lower OHRQoL. Biological mechanisms of long-term effects of T2DM on oral conditions includes vascular damage, neutrophil dysfunction, and collagen synthesis abnormalities, leading to poor wound healing and susceptibility to infection. ${ }^{3,31}$ Moderate evidence exists for a link between T2DM and periodontal diseases. Pathologic changes in gingival vasculature of patients (e.g., basement membrane thickening, angiogenesis, and increase in osmotic tissue pressure) are associated with poorly controlled T2DM. ${ }^{3}$ Researchers have shown bidirectional relationships between periodontal disease and T2DM in people with poorly controlled hyperglycemia who have a higher prevalence of periodontitis. Periodontitis may also aggravate glycemic control. ${ }^{18}$ Limited evidence explains the 
higher prevalence of dental caries in T2DM patients. ${ }^{3}$ Adults and elderly individuals with an increased probability of dental root surface exposure, become susceptible to dental root caries. ${ }^{3}$ Individuals with T2DM frequently have decreased salivary flow rates and altered saliva composition. ${ }^{3}$ Saliva normally acts as a buffer against acidic by-products of the bacterial fermentation of carbohydrates. ${ }^{3}$ If quantity or composition of saliva is reduced, protection against dental caries is also altered. ${ }^{3}$ If left untreated, caries and periodontal diseases can cause tooth loss, dental pain-related problems, and a reduced quality of life. $^{8}$

The theoretical reason for the effects of oral conditions and T2DM on quality of life includes the Lock's OHRQoL framework that adopts patient-centered outcome instruments to quantify the impact of oral conditions on daily activities with respect to individual social, psychological, and functional well-being. Dental disorders (e.g., dental caries, periodontal disease) usually affect younger individuals, and poor dental health continues throughout their lives, and may progress toward systemic diseases in absence of effective control measurements and adequate oral care. ${ }^{8}$ The cumulative impact of lifelong dental disorders and their association with systemic diseases (e.g., cardiovascular diseases, respiratory infection), increase the global burden of disease. Dental disease also contributes to limitations or disability in different dimensions of quality of life, especially those with T2DM. ${ }^{8}$ Possible limitations and disability caused by the negative effects of oral diseases on quality of life include psychological, social, and personal perceptions, in addition to health practices.

An important caveat in the interpretation of these findings is that a large proportion of the studies reviewed were of relatively poor quality, which limits 
conclusions that can be made. For example, a number of studies used only bivariate analysis with no control for potential confounders, or multivariate statistical techniques were used, but confounders were not controlled appropriately. In addition, the cut-off point of measurement scores for binary logistic regression to classify the negative impact also varied across studies, deviating from the usual convention of a 0.50 cut-off level.

This may not correctly discriminate differences in OHRQoL between participants with and without T2DM..$^{8-10,18,31,38,39}$ Eight $^{6,10,11,32,33,35,38,39}$ did not include participants without T2DM as a comparison group, limiting any conclusions. Several studies 6 631,36 used population-based samples, but they were limited to a small district or area. No study used a large nationally representative sample size. The current review of available evidence showed that some oral disease conditions (e.g., periodontitis) had a higher prevalence among T2DM adults with poor OHRQoL and low socioeconomic status. The literature indicates the need for additional studies of T2DM and OHRQoL with rigorous methods.

Limitations of the studies reviewed include the absence of control groups, small sample sizes, variation in cut-off points for binary logistic regression, and lack of theoretical basis to control for confounding factors. These inadequacies highlight the need for rigorous design and methodology of future research to better understand how T2DM and oral conditions affect on OHRQoL. The current literature review provides motivation to fill the research gaps in this important, underserved area of dental health and medicine.

\subsection{CONCLUSION}

This systematic review provided some degree of evidence for an association 
between T2DM and OHRQoL. The limited evidence available shows that people with T2DM are more likely to have poor OHRQoL. Some data support an increased susceptibility to periodontal disease and dry mouth, dental caries among individuals with T2DM. Oral conditions have an apparent negative effect on well-being and quality of life, especially for those with T2DM. The limited reviewed data document the gap in published literature regarding T2DM, OHRQoL and oral health, emphasizing the need for future research that meets a high standard. 


\section{CHAPTER 3. ORAL HEALTH-RELATED QUALITY OF LIFE IN US ADULTS}

WITH TYPE 2 DIABETES

\subsection{INTRODUCTION}

Type 2 diabetes mellitus (T2DM) has been reported to be associated with oral disorders such as periodontitis, gingivitis, dental caries, salivary dysfunctions, oral mucosal diseases, and oral infections. ${ }^{9}$ Individuals with T2DM who have hyperglycemia also have poor oral healing processes when there is an injured mucous membrane. Such injuries may result from hyposalivation, salivary chemical composition changes, decreased immune function, and diet changes. ${ }^{4,9}$ Accordingly, an increased prevalence of oral pathology is expected along with increased accumulation of plaque and calculi, and higher frequency of infections (e.g., candidiasis, periodontitis, periapical abscess).,9 Poorly controlled T2DM was associated with periodontal disease, a major cause of adult edentulism, and attendant mastication, speech, and deglutition. ${ }^{10}$ Dental caries has been shown to be more common and more severe in T2DM patients. ${ }^{4}$ Periodontal disease, which is a major cause of adult tooth loss and mastication dysfunction, are associated with poorly controlled diabetes. ${ }^{10,40}$ In addition, tooth loss and poorly fitted dentures negatively affect eating habits, restrict food choice, and contribute to nutritional imbalance and lowering quality of life. ${ }^{10}$

In addition to the clinical effects of oral diseases, it is important to include the impact of an individual's perception on his or her well-being and how this perception influences the patient's own evaluation of physical, psychological, and social 
functioning. ${ }^{10,11}$ The concept and measurement of oral health-related quality of life (OHRQoL) share this approach. ${ }^{10,13}$ OHRQoL is a self-perceived measure of an individual that oral health conditions affects quality of life related to oral functioning (e.g., chew, bite, swallow, speak), physical well-being, personal satisfaction with their appearance (e.g., smile, teeth), and social functioning (e.g., level of comfort when speaking and eating in front of other people, and pain/discomfort). ${ }^{27}$

Previous studies have investigated the factors associated with OHRQoL among T2DM patients in many countries but not the US. ${ }^{9-11,16,18}$ In the US, a few studies have been conducted to study OHRQoL only in the general population. ${ }^{41,42}$ The shortened version of the Oral Health Impact Profile (OHIP) in the 2003-2004 National Health and Nutrition Examination Survey (NHANES) cycle has been used to study the association of perceived dental needs and socio-behavioral predictors with OHRQoL in the general population. ${ }^{41,43}$ Individuals with lower socioeconomic status had more severe oral disease and poorer OHRQoL as well as limited access to dental care. ${ }^{27}$ Factors reported to be associated with oral health among T2DM patients in international studies, vary and may not be applicable to US populations, especially those with T2DM. There is a need to study OHRQoL using a nationally representative random sample collected in populations with systemic diseases, which were associated with oral conditions such as T2DM. This study's principal aim was to analyze risk factors associated with poor OHRQoL in US adults with T2DM.

\subsection{METHODS}

\subsubsection{Sampling data collection}


The NHANES 2003-2004 data were collected by National Center for Health Statistics in 50 states and the District of Columbia in the U.S. ${ }^{27}$ NHANES is a nationally representative cross-sectional survey of the US civilian, non-institutionalized population using multi-stage clustered stratified probability sampling design. ${ }^{11,41}$ The 2003-2004 NHANES data are publicly available and have 10,122 participants. ${ }^{27}$ The sample weight calculated according to NHANES analytic guidelines was used for all analyses to account for the NHANES complex sampling design, as is the usual practice for probability sampling. ${ }^{42}$

\subsubsection{Inclusion and exclusion criteria}

Only participants aged 20 or older who participated in a household interview and attended an examination center for dental screening were included in the study sample. ${ }^{41}$ Pregnant women who may have gestational diabetes were excluded from the study. After exclusion criteria were applied, the study sample had 2,945 participants representing $131,397,654$ million persons in the US.

\subsubsection{Items and scoring}

The main outcome is OHRQoL as measured by the validated OHIP questionnaire in NHANES (OHIP-NHANES). ${ }^{27,41,43}$ The survey questions ask for self-assessment of oral conditions on different dimensions of the participants' quality of life and well-being

during the last twelve months. ${ }^{11,27,41}$ Seven items of OHIP-NHANES questionnaire were used to capture seven dimensions of OHRQoL (i.e., physical pain, physical disability, functional limitation, handicap, social disability, psychological discomfort, psychological disability) as suggested in previous studies. ${ }^{27,42}$ However, in OHIP-NHANES, an item may measure multiple dimensions or one dimension may be measured by multiple items. 
We split seven items into physiological, psychological, and social domains (Table 3.4). ${ }^{30}$ Participants were asked how often they had oral disorders during the last year. ${ }^{27}$ Their responses were rated on a five-point ordinal scale and recoded as $0=$ never, $1=$ hardly ever, 2=occasionally, 3=fairly often, and 4=very often. The OHIP-NHANES scores were computed in two ways. ${ }^{27,44,45}$ The first method was a simple calculation of number of items to which a participant responded "fairly often” and "very often," which provides a frequency of the negative impacts on the individual's oral function and psychological aspects of oral health in the last twelve months. The method was termed the simple count method (OHIP-SC) and this prevalence score ranges from 0 to 7. 27,45 The second method was to sum the numeric response codes for all seven scores producing a single summative score for each participant. This method incorporated the full range of impact scores, irrespective of their frequency. It was termed the additive method (OHIP-ADD) and this severity score ranges from 0 to $28 .^{27,45}$ The severity score (OHIP-ADD) is a sum of all response categories while the prevalence score (OHIP-SC) evaluates the frequency of occurring impacts. Thus, the prevalence score overcomes limitations of an arbitrary threshold of the summary severity score. ${ }^{27}$ A higher score of OHIP-ADD or OHIP-SC indicates poorer oral health.

These scores were subsequently converted to binary values $(0,1)$ to contrast participants with lower OHRQoL scores. ${ }^{44,45}$ For the OHIP-SC, a well-established approach used is that all participants with an OHIP-SC of $>0$ were considered essentially impaired. For the OHIP-ADD, the cut-off value was heuristically chosen with the aim of the best possible discrimination between the impaired and not impaired. This cut-off point $(\mathrm{OHIP}-\mathrm{ADD}=6)$ approximated the $85^{\text {th }}$ percentile of the examination point with the 
highest total OHIP-ADD scores and was in the range of $75^{\text {th }}$ and $90^{\text {th }}$ percentile used in previous studies. ${ }^{9,34,44,45}$ Moreover, this cut-off point was used to ensure that the target groups include only participants with seriously social, physiological, and psychological oral impairments. ${ }^{44,45}$ Methodologically, this percentile cutoff shows the best possible multivariate discrimination between two resulting categories..$^{44,45}$

\subsubsection{Independent variable of interest}

T2DM status is based on the participants' self-report response to the NHANES survey question “other than during pregnancy, have you ever been told by a doctor or health professional that you have diabetes?” Participants were classified as having no T2DM if their response was "no.” Participants were classified as having T2DM with controlled HbA1c if the response was “yes” and $\mathrm{HbA} 1 \mathrm{c}<8 \% .{ }^{3}$ Participants were classified as having diabetes with uncontrolled HbA1c if the response was "yes" and HbA1c $\geq 8 \%{ }^{3}$ Instead of separately using T2DM status (yes, no) and HbA1c level ( $<8 \%$, $\geq 8 \%$ ) as two binary variables, they were combined into one variable to precisely measure the severity level of T2DM. ${ }^{3,4}$ This three-category variable avoids the redundancy in measurement of T2DM.

\subsubsection{Covariates}

Covariates were selected using the Andersen Behavioral Model of Health Care Utilization (ABM) and known associations of oral conditions with quality of life from previous studies., ${ }^{40,11,18,27,41}$ The present study adapted the ABM and the pathways of the ABM contextual factors from Baker et al study ${ }^{30}$ (Figure 1). The ABM is a validated conceptual framework to evaluate the influence of predisposing, enabling, and need factors, as well as dental care utilization on OHRQoL. ${ }^{30}$ Predisposing factors are 
population characteristics (e.g., sex, race, age, smoking status) that existed prior to poor OHRQoL. ${ }^{30}$ Enabling factors are resources such as income, dental insurance coverage, and education that enable participants to use dental care services. ${ }^{30}$ Need factors are both perceived and evaluated needs (e.g., T2DM, obesity, untreated dental caries, periodontal diseases, dentures used for tooth loss replacement). ${ }^{10,11,30}$ Untreated dental caries, periodontal disease, and evaluated unmet denture need were identified by clinical examination. ${ }^{27}$ Participants were considered obese if their body mass index $(\mathrm{BMI}) \geq 30$ $\mathrm{kg} / \mathrm{m}^{2} .{ }^{10}$ While the effect of being overweight on oral health outcomes is not clear, a large body of evidence exists showing obesity is a significant factor on the severity of diabetes and oral health outcomes, especially among those with diabetes. ${ }^{3}$ Self-report dental prophylaxis (teeth cleaning) in the last twelve months that indicated utilization of dental preventive care services was included. ${ }^{30}$

\subsubsection{Construct validity and reliability}

Our approach in evaluating construct validity was based on comparison of mean severity scores and prevalence estimates across categories (i.e., sex, African American ethnicity, dental insurance coverage) with Sanders et al study ${ }^{27}$ that also used the 20032004 OHIP-NHAES and analyzed the validity of this questionnaire. In addition, we examined Cronbach's alpha to test the internal consistent reliability of OHIP-NHANES.

\subsubsection{Statistical Analysis}

The relative effect size between the reference category value and comparison category values was calculated as the ratio of the net difference between comparisons groups divided by the reference category value. ${ }^{27}$ Statistical analyses were done using bivariate analysis and multiple logistic regression. Clinical and socio-demographic 
variables have a complex influence on OHRQoL. Therefore, the multivariate statistical approach is the most appropriate. ${ }^{45}$ Linearity of the covariates effect on outcomes (OHIPADD and OHIP-SC scores) could not be assumed, and covariates were categorized. Moreover, OHRQoL is a five-point ordinal scale, and is not a count. ${ }^{27,41,43}$ Logistic regression was thus chosen over linear regression and Poisson regression because the prevalence of poor oral health outcomes among diabetic participants is not rare.,9-11,18 Two multiple logistic regression models were used to analyze the outcome variables OHIP-ADD and OHIP-SC. These models analyzed factors associated with OHRQoL in US participants with and without T2DM. In addition, the marginal effect $(\mathrm{d} y / \mathrm{d} x)$ computed at the sample mean was also obtained after logit estimation. SAS version 9.4 statistical software (SAS Institute, Inc, Cary, NC, USA) and STATA version 16.0 statistical software (Stata Corp., College Station, TX, USA) were used to apply weights in the data set and to conduct all analyses.

\subsection{RESULTS}

\subsubsection{Participant characteristics}

The mean age in the weighted study sample was 48.5 years $( \pm 16.8)$ (Table 3.1), and more than a half of the sample was older than 45 years (Table 3.2). The sample included $48.1 \%$ males and $51.9 \%$ females. Half of the sample was former smokers and current smokers. The majority of the participants had private dental insurance coverage and college education. A third of the study population was obese. Nearly $8.7 \%$ of the participants had T2DM, and 22.3\% of T2DM participants had poor glycemic control (Table 3.2).

\subsubsection{Oral health conditions}


The average scores of OHIP-ADD (ranging 0-28) was 2.65 (standard error $(\mathrm{SE})=0.10)$ and the average proportion of OHIP-SC (ranging 0-7) was $14.17(\mathrm{SE}=0.88)$ (Table 3.1). A higher score of OHIP-ADD or OHIP-SC indicated poorer OHRQoL. According to the additive method, poor OHRQoL (OHIP-ADD $\geq 6$ ) was observed in $16.8 \%$ of participants. Using the simple-count method, poor OHRQoL (OHIP-SC $>0$ ) was observed in $14.2 \%$ participants (Table 3.2). Approximately one quarter of the study population had untreated dental caries. The sample included $12.5 \%$ and $1.8 \%$ participants clinically recommended for periodontal care and dentures, respectively. More than 58.7\% of the participants had dental prophylaxis in the last year (Table 3.2). The most common concerns were oral pain (5.8\%) among study participants and its prevalence was higher in the group with T2DM (Table 3.3). When categorized into domains, participants with T2DM have poorer reported OHRQoL in the physical and psychological domains compared to those without T2DM (Table 3.4).

The bivariate analyses found that participants with poor OHRQoL (OHIP-ADD $\geq 6$ or OHIP-SC $>0$ ) were significantly $(p<0.0001)$ more likely to have T2DM, obesity, untreated caries, periodontal disease, tooth loss, low income, smoke cigarettes, be female and African-American. Participants with good OHRQoL (OHIP-ADD $<6$ or OHIP-SC=0) were significantly $(p<0.0001)$ more likely to have private dental insurance, college education, and annual dental prophylaxis (Table 3.2).

Two multiple logistic regression models controlling for all factors identified with the ABM were used to predict the likelihood of having poor OHRQoL (OHIP-ADD $\geq 6$ or OHIP-SC $>0$ ). All predictors were significantly $(p<0.0001)$ associated with the outcome variables (Table 3.5). T2DM was associated with poor OHRQoL. T2DM participants 
with uncontrolled glycemic level had increased odds ratio (OR) of having poor OHRQoL $\left(\mathrm{OR}_{\mathrm{ADD}}=1.39\right.$; $\left.\mathrm{ORsC}_{\mathrm{SC}}=1.73\right)$, compared to those without T2DM. Similarly, T2DM participants with controlled glycemic level were more likely to have poor OHRQoL $\left(\mathrm{OR}_{\mathrm{ADD}}=1.33\right.$; $\left.\mathrm{ORsC}_{\mathrm{sC}}=1.43\right)$, compared to those without T2DM. Participants with uncontrolled and controlled T2DM's probability of having poor OHRQoL were 7.16 $\left(\mathrm{d} y / \mathrm{d} x{ }_{\mathrm{HbA}} 1 \mathrm{c}<8 \% / \mathrm{OHIP}-\mathrm{SC}=0.0716\right)$ and $4.33\left(\mathrm{~d} y / \mathrm{d} x_{\mathrm{HbAlc}} \geq 8 \% / \mathrm{OHIP-SC}=0.0433\right)$ percentage points higher than those without T2DM, respectively. The risk factors of having poor OHRQoL (in descending order) were current smoking (ORsc-current-smoker=1.99), untreated dental caries $\left(\mathrm{ORsC}_{\mathrm{sc}}=1.79\right)$, uncontrolled T2DM (ORsc-uncontrolled=1.73), unmet denture need ( $\left.\mathrm{ORsc}_{\mathrm{sc}}=1.72\right)$, female (ORsc=1.66), obesity (ORsc=1.24), American-American $(\mathrm{ORsc}=1.19)$, and periodontal disease $(\mathrm{ORsc}=1.003)$. The preventive factors of poor OHRQoL were dental private insurance $(\mathrm{ORsc}=0.81)$, annual dental prophylaxis $(\mathrm{ORsc}=0.83)$, and college education $(\mathrm{ORsc}=0.85)$ (Table 5).

\subsubsection{Construct validity and adequacy}

Severity scores estimates were markedly similar with Sanders et al study ${ }^{27}$ (Table 3.1). For example, the average severity scores of the present study were 2.65 compared to 2.81 of the comparison study. ${ }^{27}$ Moreover, the present study's prevalence estimates (14.17\%) differed by 1.13 percentage point with the comparison study ${ }^{27}$ (15.3\%). The relative effect of sex prevalence was also relatively similar (45\% vs 38\%). The present study's Cronbach's alpha based on standardized items of OHIP-NHANES were 0.84, which is greater than 0.70 indicating acceptable internal consistency reliability.

\subsection{DISCUSSION}


The present study makes three important contributions. This investigation is the first analysis of OHRQoL in the US adults with T2DM at the population level using the range of socioeconomic, dental care utilization, and clinical oral examination parameters. It is one of very few studies that report OHRQoL among T2DM adults at the population level. Researchers have used national data to study OHRQoL in the general population in the United States and other countries (e.g., United Kingdom, Australia, Finland, Germany), ${ }^{27}$ but only samples of convenience with relatively small sample sizes were used to study OHRQoL among T2DM populations..$^{10,11,18}$ The second contribution is confirmation of the association between T2DM and poor OHRQoL in US adult populations, especially those with uncontrolled T2DM. The third contribution is additional evidence of risk and preventive factors of OHRQoL in US adults. Specifically, OHRQoL impairment's risk factors among US diabetic adults, whether defined as OHIP$\mathrm{ADD} \geq 6$ or as OHIP-SC $>0$, included untreated dental caries, unmet denture needs, low income, African-America, and smoking. In contrast, the protective factors for OHRQoL impairment were private dental insurance, college education, and annual dental prophylaxis.

The OHIP-SC (prevalence score) method yielded stronger evidence for an association of the study factors with impaired OHRQoL than did the OHIP-ADD (severity scores) method. One possible explanation for this variation is that the prevalence scores (OHIP-SC) only count the frequency of "fairly often" and "very often" but not "occasionally."27 Having the symptoms "fairly often” and "very often” may truly and better reflect the impact of oral conditions on participants' perceived oral health than having the symptoms "occasionally."27 Although the magnitude of OR and marginal 
effect were different in OHIP-ADD and OHIP-SC, they were still close and in the same direction. One limitation of this study is the cross-sectional study design and time since the sample was collected. The NHANES was designed to provide prevalence estimates at the population level, and it is appropriate to use it for studying the impact of oral conditions on quality of life in US adult population with T2DM. ${ }^{27}$ Clinical information is needed to build a stronger model for the study.

In comparison with previous studies, researchers in France (GOHAI, $n=316$ ), ${ }^{10}$ India (GOHAI and OHIP-14, n=110), ${ }^{17}$ Pakistan (OHIP-14, n=101), ${ }^{34}$ and Iran (GOHAI and OHIP-14, $\mathrm{n}=350)^{9}$ also found that T2DM had a negative impact on OHRQoL. In contrast, researchers in the United Kingdom (OHIP-49, n=135) ${ }^{16}$ and Iran (OHIP-20, $\mathrm{n}=200)^{18}$ did not find a significant association between OHRQoL and T2DM. Our findings add evidence that participants with uncontrolled T2DM were more likely to have poor OHRQoL comparing people without diabetes or with controlled diabetes. Those with poorly controlled diabetes have lower stimulated parotid flow rates. ${ }^{3}$ Among people with diabetes, $24-48 \%$ were found to have asymptomatic bilateral enlargement of the parotid glands, and those with uncontrolled diabetes had a greater probability of the enlargement. ${ }^{3}$ Moreover, people with uncontrolled diabetes can have decreased saliva flow, which may cause dry mouth and allow bacteria to accumulate easier. ${ }^{3}$ These changes increase the risk of developing bad breath, tooth decay, and gum diseases that may lead to difficulty in chewing, speaking, swallowing, and tasting. ${ }^{3}$ In contrast with previous studies, ${ }^{10,17,34}$ our findings provide suggestive evidence for an association between obesity and poor OHRQoL. One of the possible biological reasons is that obesity is closely related to insulin resistance, which is a mechanism involved in chronic 
diabetic's oral complications and may cause vascular damages. ${ }^{3}$ A US study using a large cohort suggested that insulin resistance is a mediator of the link between obesity and severe periodontitis. ${ }^{3}$ Our findings indicate that periodontal disease appeared to be a risk factor of OHRQoL (OROHIP-ADD=1.07, OROHIP-SC =1.003). However, participants with periodontal disease's predicted probability of having poor OHRQoL was just less than one percentage point $(\mathrm{d} y / \mathrm{d} x$ OHIP-ADD $=0.94 \%, \mathrm{~d} y / \mathrm{d} x$ OHIP-sc $=0.3 \%)$ compared to those without the disease. Indeed, previous studies have unequivocally shown that the level of glycemia was disproportionally associated with increasing periodontitis risk, and the probability of later tooth loss. ${ }^{3}$ For this reason, it is justified to search for risk groups prone to develop severe periodontitis as a consequence of high glycemia or uncontrolled T2DM. $^{3}$

In addition, dental caries were reported to be associated with poorer oral health ${ }^{2}$ and quality of life in general populations, ${ }^{27,44,45}$ and the present study adds more evidence of the association between the oral conditions and impaired OHRQoL in T2DM participants to the literature. The present study found that evaluated unmet denture need was associated with poor OHRQoL because it may negatively affect eating habits, restrict food choice, and contribute to nutritional imbalance and lowering quality of life. ${ }^{3}$ Smoking had a negative impact on oral outcomes and overall health, ${ }^{4}$ and could explain why T2DM former smokers were more likely to have poor OHRQoL compared to never smoker. The former smokers were less likely to have impaired OHRQoL compared to "current smokers." Specifically, smoking had the largest marginal effects as the current smoker s' probability of having poor OHRQoL ( $\mathrm{d} y / \mathrm{d} x$ OHIP-ADD $=0.0958$ ) would be 9.58 percentage points higher than the never smoker. Therefore, the provision of smoking 
cessation and targeted health education, especially for those with T2DM should be considered to establish an interdisciplinary and collaborate approach to improve OHRQoL for this vulnerable population. ${ }^{40,46}$ Dental insurance has a positive impact on dental care utilization, oral health outcome, and OHRQoL in general population. ${ }^{42,43,46}$ The present study is the first investigation to find that private insurance coverage and annual prophylaxis are associated with higher average OHRQoL among participants with T2DM. People with difficulties in access to oral care may also have barriers in access to general medical care, which may be an explanation for common risk factors between poorly controlled T2DM and OHRQoL. ${ }^{42,43,46}$

This cross-sectional study has implications for public health, dental practice, policymakers, and for the future studies of OHRQoL. From a public health perspective, the findings indicate preventable risk factors (e.g., uncontrolled T2DM, obesity, smoking) for impaired OHRQoL. For example, dentists should advise their T2DM patients to check HbA1c at least four times a year ${ }^{3}$ and explain adverse effects of untreated dental caries and periodontal disease, emphasizing that those conditions are preventable. ${ }^{3,4}$ From a policy perspective in the US, national surveys (e.g., NHANES) should routinely include OHRQoL to evaluate progress of improving the quality of life for all Americans. Future studies should use more recently collected data that includes the effects of providing access to basic oral care services (e.g., dental prophylaxis, fillings, blood sugar testing in dental office) and health education (e.g., smoking control, weight control) on OHRQoL for T2DM patients, especially those with low income.

\subsection{CONCLUSION}

OHRQoL was poorer among US adults with T2DM, especially those with 
uncontrolled glycemia. Risk factors of poor OHRQoL are untreated dental caries, periodontal disease, unmet denture needs, obesity, female gender, African American, and low income. Higher education, private dental coverage, and annual dental prophylaxis was associated with higher OHRQoL. Providing dental insurance with sufficient coverage for oral care services (e.g., prophylaxis, dental fillings), controlling HbA1c level, losing weight, and smoking cessation could improve oral health for US T2DM patients, and OHRQoL. 
CHAPTER 4. LINKS BETWEEN ORAL HEALTH-RELATED QUALITY OF LIFE IN US ADULTS AND TYPE 2 DIABETES: STRUCTURAL EQUATION MODELING

\section{ANALYSIS}

\subsection{INTRODUCTION}

The increasing prevalence of type 2 diabetes mellitus (T2DM) and attendant comorbidities (e.g., vascular complications, respiratory infections, periodontal diseases, tooth decay, tooth loss) provide several public health motivations for prevention of acute and chronic oral complications. ${ }^{3}$ One expected outcome of these prevention efforts is improved quality of life for people with T2DM. Individuals with T2DM and hyperglycemia (poorly controlled diabetes, HbA1c>8\%) also have poor oral healing of injured mucous membrane. ${ }^{3}$ Oral cavity injuries may result from hyposalivation, salivary chemical composition changes, decreased immune function, and diet changes. ${ }^{3}$ Accordingly, prevalence of oral pathology is expected to increase in association with increased plaque and calculi accumulation and higher frequency of infections (e.g., candidiasis, periodontitis, periapical abscess). ${ }^{9}$ Importantly, poorly controlled T2DM is associated with periodontal disease, a major cause of adult edentulism, and attendant problems with mastication, speech, and deglutition. ${ }^{4,10}$ Tooth loss and poorly fitting dentures negatively affect eating habits, restrict food choice, and contribute to nutritional imbalance, and lowers quality of life. ${ }^{10} \mathrm{~T} 2 \mathrm{DM}$ associated with oral disease have negative effects on daily living and quality of life. ${ }^{10}$

In addition to the clinical impact of dental diseases, personal perception of one's 
well-being influences an individual's valuation of physical, psychological, and social functioning. ${ }^{10}$ Oral health-related quality of life (OHRQoL) is a multidimensional selfreport instrument that assesses oral health effects on day-to-day functions. ${ }^{13}$ OHRQoL in adults is measured using the Oral Health Impact Profile (OHIP). ${ }^{27,41,43}$ The National Health and Nutrition Examination Survey 2003-2004 (NHANES) included a seven-item validated version of the OHIP instrument (OHIP-NHANES), with established psychometric adequacy. ${ }^{27,41,43}$ The OHIP-NHANES was previously used to analyze the association of perceived dental needs and socio-behavioral predictors with OHRQoL in US adults. ${ }^{41,43}$

Adjusting for demographics factors, those studies found that OHRQoL was strongly associated with evaluated and perceived treatment need, general medical health, personal health practices, and use of dental services. ${ }^{41,43}$ Unlike traditional regression models that evaluate the effects of predictors on OHRQoL while holding the effects of covariates constant, structural equation modeling (SEM) test all relevant direct and indirect pathways of factors that simultaneously predict OHRQoL. ${ }^{43}$ A few studies ${ }^{30,47}$ attempted to use SEM to test causal pathways of contextual factors associated with OHRQoL using samples of general population. Baker et al study ${ }^{30}$ was the first published article used SEM to analyze causal effects of contextual factors of Andersen Behavioral Model of Health Care Utilization (ABM) that predicts OHRQoL of adults in the United Kingdom (UK). Such study provides stronger evidence for UK policymakers that may allow them to see the effects of their policy intervention and other factors simultaneously affecting OHRQoL, comparing to traditional regression models. However, no published studies used SEM to analyze all factors simultaneously as a system of multiple direct and 
indirect pathways of ABM factors that predict OHRQoL in a US population with systemic disease such as T2DM.

This study uses a simplified three-factor (ABM) as a theoretical framework to test causal pathways between T2DM and contextual factors associated with OHRQoL. Specifically, we hypothesize that T2DM would predict need, which in turn, would have direct and indirect effects on OHRQoL. Need would also predict personal health practices and use of services. Personal health practices and use of services predicts OHRQoL. The overarching goal of this investigation is to analyze OHRQoL and oral health, ultimately deriving an applied model to improve access to dental care services for this T2DM vulnerable population. The principal aim of this study was to apply SEM to a simplified ABM to analyze the causal effects of T2DM and other factors on OHRQoL in adults from a nationally representative survey in the US.

\subsection{METHODS}

\subsubsection{Study Sample}

All non-pregnant participants aged 20 years or older in the 2003-2004 NHANES who provided complete data for the OHIP-NHANES (i.e., participated in a household interview, attended an examination center for dental screening) were included in the study sample ${ }^{41}$ resulting in 2,798 unique individuals in the study sample. The NHANES survey used multi-stage probability cluster sampling design, ${ }^{42}$ and provided the weights for us in future analysis. The weighted sample represented 124,525,899 individuals in the US population.

\subsubsection{Conceptual Framework}


The ABM conceptual framework guided the analysis of the association of oral health conditions and OHRQoL building on prior studies. ${ }^{3,4,10,11,18,27,30,41}$ The present investigation adapted a simplified ABM to analyze contextual factor pathways from Baker et al study ${ }^{30}$ to evaluate the causal effects of T2DM on need. Need affects personal health practices and use of services, and OHRQoL. The model is fully adjusted for demographics such as education level and income range. ${ }^{30}$ Predisposing factors (participant demographics that are associated with higher rate of poor OHRQoL) and enabling factors (resources that enable participants to use dental care services) were simplified by modeling these effects as covariates (e.g., education, income), instead of latent variables. A solution was not computationally possible when predisposing factors (e.g., gender, race) were included in the model. Need factors include perceived and evaluated medical and dental treatment needs. ${ }^{3,10,11,30}$ T2DM was used as an independent variable instead of an indicator of the need latent variable to avoid multi-collinearity. This modification of the model can improve measurement of oral health care need.

\subsubsection{Measures}

Measured indicators were selected based on the ABM and prior studies. ${ }^{3,4,10,11,18,27,41}$ The model included three latent variables (need, personal health practices and use of care, and OHRQoL), one independent variable of interest (T2DM), and two covariates (education and income). Latent and measured variables used in the analysis are described in Table 4.1.

\subsubsection{Need}

The need latent variable includes three measured ordinal variables: evaluated need, perceived treatment need, and general health condition. Evaluated need was 
assessed by clinical recommendation of restorative, periodontal, and denture care. Evaluated need was coded ordinally as $1=$ no need, $2=$ one of the three treatments, $3=$ two of the three treatments, $4=$ all three treatments. Perceived need was assessed by responses to the questions "Do you need...teeth filled/gum treatment or teeth cleaned/dentures made?” Responses were coded as $1=$ no need, $2=$ one of the three treatments, $3=$ two of the three treatments, $4=$ all three treatments. General medical health condition was assessed

by responses to the following question: "Would you say your health in general is..." and coded as $1=$ =xcellent, $2=$ very good, $3=$ good, and $4=$ fair or poor.

\subsubsection{Personal health practices and use of services (noted as use and}

\section{behavior)}

The personal health practices and use of dental services included three measured ordinal variables: reason for dental visit, frequency of dental visits, and smoking status. Reason for dental visit was reported using the following question: "What was the main reason you last visited the dentist?” Responses were coded as 1="Went in on own for check-up, examination, or cleaning”; 2="Was called in by the dentist for check-up, examination, or cleaning”; 3="Something was wrong, bothering or hurting”; 4="Went for treatment of a condition that dentist discovered at earlier checkup or examination”; 5=Other reasons. Frequency of dental visits was assessed in response to: "When did you last visit a dentist?” Responses were coded as $1=$ =six months or less, $2=$ more than six months, but not more than one year ago, $3=$ =more than one year, but not more than two years ago, $4=$ =more than two years ago, but not more than three years ago, $5=$ more than three years, but not more than five years ago, $6=$ more than five years ago, $7=$ never have been to a dentist. Smoking status was evaluated in response to number of cigarettes 
participants smoked in their lives. Responses were coded as $1=$ "never smoked" if they have never smoked, or smoked less than 100 cigarettes in their lives, coded as $2=$ "former smoker" if they have smoked at least 100 cigarettes in their lives but they had quit smoking at the time of interview. Participants were coded as $3=$ "current smoker" if they have smoked at least 100 cigarettes in their lives and currently smoke cigarettes. ${ }^{48}$

\subsubsection{Perceived oral health outcomes}

Perceived oral health outcome was measured by OHRQoL using OHIP-NHANES and included three measured sub-scales variables: OHIP-physical, OHIP-psychological, and OHIP-social. OHIP-NHANES assesses the participants' frequency of oral healthrelated problems on seven dimensions during the previous twelve months. ${ }^{11,27,41}$ Participants were asked to rate for the last twelve months each item on a five-point ordinal scale and coded as: 1=never, $2=$ hardly ever, $3=$ occasionally, $4=$ fairly often, and $5=$ very often. Three subscales were created to represent the three functional domains, physical, social, and psychological. Responses to items OHQ.620, OHQ.630, OHQ.650, OHQ.660, and OHQ.670 were summed to represent physical function (range 5-25). ${ }^{27}$ Item OHQ.680 represented psychological function (range 1-5); Item OHQ.640 represented social function (range 1-5). ${ }^{27}$

\subsubsection{Variable of interest}

The main independent variable of interest was T2DM status as assessed in response to the NHANES survey question: "other than during pregnancy, have you ever been told by a doctor or health professional that you have diabetes?” Responses were coded as 1=do not have T2DM if their response was "no.” Responses were coded as 2=participant had T2DM with controlled HbA1c if the response was "yes" and HbA1c 
$<8 \% .{ }^{3}$ Responses were coded as 3=have T2DM with uncontrolled HbA1c if the response was "yes" and $\mathrm{HbAlc} \geq 8 \%{ }^{3}$

\subsubsection{Covariates}

Participant education level was classified into five levels and coded as: 1=bachelor's degree or above, $2=$ =associate degree or some college, $3=$ high school diploma, $4=9-11^{\text {th }}$ grade, $5=$ less than $9^{\text {th }}$ grade. Participants' income was categorized and coded as: $1=$ if their income $>400 \%$ FPL, as 2 if their income between 200 and $400 \%$ FPL, as 3 if their income $<200 \%$ FPL. All variables were coded in reverse order to make them in the direction of risk. The higher numbers indicate the larger risk of the variable.

\subsubsection{Statistical Analysis}

Traditional two-stage SEM was used. ${ }^{30,47,49}$ Confirmatory factor analysis (CFA), the first step of SEM was employed to test whether the indicators selected for the hypothesized measurement models have an acceptable factor structure. ${ }^{30} \mathrm{SEM}$ is an appropriate statistical technique to assess and modify the theoretical framework because it allows simultaneous testing of complex interrelationships between variables specified within an a priori model. ${ }^{30,49}$ CFA measures the relationship between observed (indicator) items (i.e., evaluated need, perceived treatment need, general health condition) and the unobserved underlying (latent) constructs (e.g., need factors). After specifying the measurement model, the hypothesized SEM was tested to explore the a priori direct and indirect relationships between T2DM and latent variables (i.e., need, personal health practices and use of services, OHRQoL).

\subsubsection{Confirmatory factor analysis}


The initial step of the analysis was to test whether the data are consistent with the hypothesized three-factor model, a simplified ABM version. The three latent variables were oral health care need, personal health practices and use of services, and OHRQoL. Indicators were not allowed to load on more than one factor (construct). ${ }^{49}$ In addition, error terms were orthogonal. ${ }^{49}$

The overall model fit was assessed using the chi-square test statistic $\left(\chi^{2}\right)$ and five supplemental fit indexes used in previous studies: ${ }^{30,47,49}$ root-mean-square error of approximation (RSMEA) with 90\% CI, standardized root mean square residual (SRMR), the Goodness of Fit Index (GFI), the Normed Fit Index (NFI), the Incremental Fit Index (IFI), the Tucker-Lewis index (TLI), and the comparative fit index (CFI). ${ }^{30,47,49}$ The chisquare statistic divided by degree of freedom ( $\chi^{2} /$ d.f. $)$ ratio was used as the measure of overall goodness-of-fit and was reported because the chi-square statistic can be inflated by sample size..$^{30,47,49}$ The goodness of fit model was indicated by a $\chi^{2} /$ d.f. ratio $\leq 5.00$, RMSEA values $\leq 0.06$, GFI, NFI, IFI, CFI, and TFI values $\geq 0.90$, and a SRMR value $\leq 0.08 .^{30,47,49}$

\subsubsection{Structural equation modeling (SEM)}

After an adequate measurement model was specified, a structural model was tested to estimate the direction and magnitude of the direct and indirect lagged paths between T2DM and the three latent variables. As hypothesized, need would predict personal health practices and use of services. The personal health practices and use of services factor predicts OHRQoL. Need and personal health practices and use of services factors predict OHRQoL. In previous studies ${ }^{3,10}$ that measured the association between T2DM with oral and medical conditions, T2DM was hypothesized to predict need, and 
OHRQoL mediated by need. Demographic variables (i.e., education, income) were included to control for possible effects of education and income.

\subsubsection{Statistical software}

SAS version 9.4 statistical software (SAS Institute, Inc., Cary, NC, USA) was used for data management and descriptive statistics. Version 1.1.3.1 of the Complex Survey Structural Equation Modeling packages (lavaan.survey) in R software was used for CFA and SEM. Total effects were estimated using the lavaan.survey package in R. The total effects include direct effects of a path from one variable to another (e.g., from T2DM to need) and indirect effects, a path mediated through other variables (e.g., the path from need to OHRQoL through personal health practices and use of services). Many indicators were non-normal and categorical, which prevented use of the standard maximum likelihood estimation method. As recommended in the literature, the alternative was to use a diagonally weighted least squares (DWLS) derived by Muthén. ${ }^{24}$ Standardized path coefficient estimates were calculated using the lavaan.survey $\mathrm{R}$ package because the model contained measured variables with different units. ${ }^{24}$

\subsection{RESULTS}

\subsubsection{Participant characteristics}

In the weighted sample ( $\mathrm{N}=124,525,899), 51.9 \%$ of the participants were female, and $48.1 \%$ were male. The mean age was 48.63 years (standard deviation (SD)=16.84, range $=20-85$ ). Nearly $8.5 \%$ of the participants had T2DM, and $22.4 \%$ of T2DM participants had poor glycemic control (i.e., HbAlc $\geq 8 \%$ ) (Table 4.1).

\subsubsection{Confirmatory factor analysis}


The simplified three-factor ABM (measurement model - Model 4.1) was a good fit to the data meeting seven of the a priori criteria (see Table 4.2 and Figure 4.1). Standardized correlation and factor loading $(\lambda)$ estimates for this three-factor measurement model are shown in Figure 4.1. Factors (latent variables) are in ellipses, indicators (measured variables) are in rectangles, and residual errors terms (variances) in circles. All hypothesized correlation estimates between three latent variables were significant $(p<0.001)$ in this CFA model. In addition, in Figure 4.1 and Table 4.3, the three factors had correlations ranging from $\boldsymbol{\theta}=0.30$ and $\boldsymbol{\theta}=0.78$, indicating that they had acceptable discriminant validity (i.e. $<0.85){ }^{19,24}$

In Table 4.3, factor loadings $(\lambda)$ were significantly associated $(p<0.001)$ in the expected direction. Higher perceived and evaluated need for dental treatments, and worse general (medical) health conditions were significantly associated with high scores on the “need" factor. Perceived need $(\lambda=0.59)$ had a greater factor loading than evaluated need $(\lambda=0.40)$. Oral problems as a reason for dental visit, infrequent visits to the dentist in the last twelve months, and current smoking were strongly associated with the "personal health practices and use of services” factor. The best indicator of personal health practices and use of services was the reason for dental visit $(\lambda=0.70)$. The second-best indicator was frequency of dental visits $(\lambda=0.40)$. Higher scores of physical, psychological, and social domains of OHIP were associated with more of poor OHRQoL factor (measured by OHIP-NHANES). The best indicator of OHRQoL was OHIPPhysical with a factor loading of $(\lambda=0.75)$. The other two items had similar factor loadings, which were $\lambda=0.68$ and $\lambda=0.67$ for OHIP-Psychological and OHIP-Social, respectively. 


\subsubsection{Structural equation modeling}

The next step was to test the direct and indirect paths between T2DM and latent variables in the simplified three-factor ABM (Figure 4.2 and Table 4.4). In the model, the hypothesized paths were all significant, including the paths from T2DM to need (denoted as $\mathrm{T} 2 \mathrm{DM} \rightarrow$ need), from need to personal health practices and use of services, from need to OHRQoL, from personal health practices and use of services to OHRQoL, and from education to personal health practices and use of services, from income to personal health practices and use of services. In addition, need indirectly predicts OHRQoL. This model fit the data well (Table 4.2, Model 4.2). Explained variance was 23.8\%, 59.7\%, and 18.1\% for need, personal health practices and use of services, and OHRQoL, respectively (Figure 4.2).

\subsubsection{Direct effects}

The hypothesized direct effects $(\beta)$ were significant in the tested model (Table 4.4). Worse T2DM status was predictive of higher need $\left(\beta_{\mathrm{T} 2 \mathrm{DM} \rightarrow \text { need }}=0.49, p<0.05\right)$. Higher need predicted worse personal health practices and use of services $\left(\beta_{\text {need } \rightarrow \text { use and }}\right.$ behavior $=0.46, p<0.001)$. Higher need also predicted lower OHRQoL $\left(\beta_{\text {need } \rightarrow \text { OHRQoL }}=0.30\right.$, $p<0.001)$. A comparison of the direct path $\left(\beta_{\text {need } \rightarrow O H R Q O L}=0.30\right)$ with total effects $\left(\omega_{\text {need } \rightarrow O H R Q o L}=0.39, \mathrm{p}<0.001\right)$ indicated that the impact of need on OHRQoL was a $77 \%$ (or $\frac{0.30}{0.39}=0.77$ ) direct effect. In addition, worse personal health practices and use of services had an impact on lower OHRQoL ( $\left.\beta_{\text {use and behavior } \rightarrow \text { OHRQoL }}=0.19, p<0.001\right)$. Worse personal health practices and use of services was predicted by education $\left(\beta_{\text {education } \rightarrow \text { use and }}\right.$ behavior $=0.37, \mathrm{p}<0.001)$ and income $\left(\beta_{\text {income } \rightarrow \text { use and behavior }}=0.32, p<0.01\right)$.

\subsubsection{Indirect effects}


Similarly, the indirect effect between need and OHRQoL was significant and aligned within the hypothesized model (Table 4.4). Higher scores on the need factor predicted lower OHRQoL $\left(\alpha_{\text {need } \rightarrow \text { OHRQoL }}=0.09, p<0.001\right)$. The impact of need on OHRQoL was $23 \%$ (or $\frac{0.09}{0.39}=0.23$ ) indirect.

\subsection{DISCUSSION}

\subsubsection{Principal findings}

The present study's findings support the three-factor ABM hypotheses that (1) T2DM predicted need, (2) need had direct and indirect effects on OHRQoL, and (3) need predicted personal health practices and use of services. In turn, personal health practices and use of services predicted OHRQoL. Specifically, this study analyzed several social and behavioral factors important to improve the understanding of oral health in the adult T2DM population in the US in 2003-2004. T2DM had influences on need for oral care. The coefficient of the path from T2DM to need was $0.49(p<0.05)$, indicating T2DM would strongly predict need of dental care treatment.

\subsubsection{Strengths and weaknesses of the study}

The present study is one of a few reports to explore key determinants of dental service use, OHRQoL, and their interrelationships in adult T2DM populations. This study provides findings important to test complex relationships between key contextual factors when oral health is evaluated through direct and indirect paths. For example, in Table 4.4 and Figure 4.2, the total effect (including direct and indirect) of need on OHRQoL was $\omega=0.39$. The indirect effect of need $(\alpha=0.09)$ on OHRQoL was mediated by personal health practices and use of services. Importantly, the need factor was constructed by combining evaluated treatment need, perceived need, and general health conditions. 
Surprisingly, in Table 4.3, perceived treatment need's factor loading $(\lambda=0.59)$ was much larger than the evaluated need $(\lambda=0.40)$. This indicates that patients may evaluate the impact of oral treatment need differently from their dentists based on various aspects of their lives. General health conditions had a factor loading of 0.57 , indicating that it had an important effect on need. In addition, the greatest impact of OHRQoL was physical functioning $(\lambda=0.75)$, followed by psychological functions $(\lambda=0.68)$, and then social functioning $(\lambda=0.67)$ in the measurement model. The factor loadings of psychological and social functioning were relatively small compared to physical function. Psychological and social functioning were measured by a single OHIP item for each function, "embarrassed because of mouth conditions" and "had difficulty with job because of mouth conditions," but were significant. CFA results support the importance of these dimensions in OHRQoL.

\subsubsection{Relations to other studies}

The present study used a three-factor ABM, instead of five factors as depicted in the full ABM used in Baker's study, the study adapted for this analysis. ${ }^{30}$ Predisposing and enabling factors were not included in the simplified model. However, the pathways of predisposing factors to four other factors of the full ABM were not significant in Baker's SEM study. ${ }^{30}$ In the present study, education and income were used as covariates instead of measured indicators of latent variables (e.g., predisposing, enabling). Education and income significantly influenced personal health practices and use of services. Higher levels of education and income were associated with favorable attitudes toward oral health. ${ }^{30}$ 
Social structural factors (e.g., attitudes, beliefs, and knowledge about the oral health and dental services) may increase explanatory power when added to the ABM models. ${ }^{30}$ According to the Theory of Planned Behavior, ${ }^{50}$ an individual's intention to perform a behavior (e.g., going to see a dentist for a check-up, exam, or cleaning) is a result of beliefs (e.g., attitudes, values, and knowledge about oral health and dental services). ${ }^{30}$ These social structural factors may influence enabling resources, need, and a pattern of preventive oral care services. ${ }^{30}$ This may explain why "the reason for dental visit” had the largest factor loading $(\lambda=0.70)$, higher than the factor loadings for frequency of dental visits $(\lambda=0.40)$ and smoking $(\lambda=0.36)$ in the measurement of personal health practices and the use of services. Moreover, participants with favorable attitudes toward dental care were more likely to have better evaluated oral health outcomes. ${ }^{30}$ Conversely, individuals with negative attitudes toward dental care and lower income had the poorest oral health, cost-related treatment delays, and smoked cigarettes. ${ }^{30}$ In the present study, smoking, problem-oriented dental visits, and frequency of dental visits were linked to OHRQoL. This finding contradicts a previous SEM study using United Kingdom (UK) data. ${ }^{30}$ The UK study found that less frequent brushing, not visiting the dentist annually, and only visiting a dentist when there is pain were linked to better OHRQoL. ${ }^{30}$ The difference may partially be the result of the way latent constructs were operationalized. Nonetheless, the present findings intuitively align with a large body of evidence that recent dental clinic attendance, a preventative pattern of dental care, and good oral habits have a positive effect on evaluated and perceived oral health outcomes. ${ }^{4,30}$ More importantly, previous studies found a strong association between T2DM and oral health. Researchers also suggested an association between T2DM and 
OHRQoL. The new finding of the present study is that the T2DM has a direct effect on need, and in turn need affects personal health practices and use of services and OHRQoL.

\subsubsection{Clinical and policy implications of the study}

Given the advantages of SEM over traditional regression, the causal pathways of contextual factors associated with OHRQoL were simultaneously evaluated in the present study provide clinical and policy implications for clinicians, policymakers, and health policy researchers. For example, when policymakers design a policy or intervention program to improve OHRQoL for individuals with T2DM, they do not need to hold factors associated with OHRQoL constant. For example, in the present study, T2DM appears to play an important role in the need for dental treatments, that in sequence affect personal health practices and OHRQoL. Simultaneously, a dental preventive program may have different interventions to reduce modifiable risk factors and improve protective factors of OHRQoL, but the program will be still able to evaluate the effects of all interventions on OHRQoL. For example, we found that perceived need for treatment had the greatest effect on need and the reason for dental visits had the greatest influence on personal health practices, we can design a health policy to simultaneously improve individual perception of oral care need and provide benefits of regular dental check-ups for T2DM individuals with low income ( $<200 \%$ FPL). However, we will still be able to simultaneously evaluate the effects of these interventions, instead of designing a health policy to intervene one factor at a time. Similarly, the dental program may simultaneously encourage dentists to recommend T2DM patients to check HbA1c before a dental visit. Health education programs to improve oral health attitudes and T2DM individuals should be the focus of these dental preventive programs. In addition, the 
present study demonstrates the advantage of SEM over simple descriptive research. However, SEM statistical modeling is not a panacea as it is only suitable for research problems in which direction of causality is intuitive. ${ }^{19}$ The findings help physicians, dentists and health policymakers better understand casual pathways between T2DM and perceived oral health outcomes (OHRQoL) to have appropriate treatments and policy for this vulnerable population.

\subsubsection{Limitations and future research}

The present study used SEM because it is a valid statistical technique for theorydriven analysis, but the causal relationships between items and constructs must be conceptually clear. ${ }^{30}$ The revised ABM from 1995 contained some concepts are broadly defined and overlapping, which may lead to difficulty for implementation. ${ }^{30}$ For example, income and education were modelled as predisposing or enabling factors in previous studies. ${ }^{28,30}$ Income and education may be both predisposing and enabling factors, but it is not possible analytically for an item to have multiple latent construct roles. ${ }^{28,30}$ It is challenging to conceptualize and appropriately apply rigorous statistical modeling to examine determinants of need, personal health practices and use of dental care services, and key oral health outcomes. Clarifying these confusing conceptual issues will help devise and incorporate valid indicators to adequately capture the underlying concepts. ${ }^{30}$ Moreover, NHANES data was collected in a sample designed to be representative US population using probability cluster sampling, some of whom had T2DM. ${ }^{27}$ In future studies, oversampling T2DM individuals would provide more data on this vulnerable population. The findings of oral care utilization in the present investigation may only be applicable to the structure of dental policy in the USA. Further studies are needed, and 
they should use samples from other countries with different dental public health policies to cross-validate the present findings.

\subsection{CONCLUSION}

The new finding reported is the empirical analysis of causal pathways of the interrelationships of T2DM, need, personal health practices and use of services with OHRQoL in a simplified three-factor ABM. The present study found that T2DM had an impact on need, which in turn, had direct and indirect effects OHRQoL. Further refinement and replication of the model developed in this investigation in future studies that analyze the causal effects of T2DM on OHRQoL is needed. This will help improve dental public health policy for this T2DM vulnerable population by better understanding the causal pathways of T2DM to OHRQoL in the ABM. 


\section{CHAPTER 5. CONCLUSION}

\subsection{SUMMARY}

This dissertation focused on the relationships between T2DM and OHRQoL and factors that affect the relationship in the US. The objectives of the dissertation research were a three-step process: (1) to analyze existing literature on relationships of T2DM with poor OHRQoL, codify published analyses of risk and preventive factors that affect this association, and identify research gaps in the literature, (2) to analyze risk factors associated with poor OHRQoL in US adults with T2DM using a nationally representative random sample, and (3) to apply SEM to a simplified ABM to analyze the causal effects of T2DM and other factors on OHRQoL among adults from a nationally representative survey in the US. The first, second, and third objectives were met in Aim 1, Aim 2, and Aim 3, respectively.

In Aim 1, 16 empirical articles were included in a systematic review that examined the association between T2DM and OHRQoL. Half of the reviewed studies $(\mathrm{N}=8)$ did not include a control group (participants with non-T2DM). All investigations used samples of convenience, or surveys at the community level outside of the US. No studies were conducted at the national level in the US. Five of the included studies used only bivariate analysis and did not control for confounders. The remaining 11 studies used multivariate analysis, but none of them used a theoretical framework to guide their approach. Limited evidence supported the association between T2DM and poor 
OHRQoL. However, some data supported an increased susceptibility to periodontal disease and dry mouth, dental caries that may have negative effects on well-being and quality of life among individuals with T2DM.

In Aim 2, the 2003-2004 NHANES data set was used. The sample included 2,945 participants aged 20 or older, representing 131,397,654 million persons in the US population in a weighted sample analysis. Multiple logistic regression was used to analyze OHIP-ADD and OHIP-SC scores, and the ABM model was used as a theoretical framework. We found that OHRQoL was poorer among US adults with T2DM, especially those with uncontrolled glycemia. Risk factors of poor OHRQoL are untreated dental caries, periodontal disease, unmet denture needs, obesity, female gender, African American ethnicity, and low income. Higher education (some college), private dental coverage, and annual dental prophylaxis was associated with higher OHRQoL.

In Aim 3, a sample of 2,798 participants aged 20 or older representing $124,525,899$ individuals in the US population in a weighted sample analysis was used. SEM was used in a simplified three-factor ABM to analyze the causal effects of T2DM and other factors on OHRQoL. Causal analysis pathways of the interrelationships of T2DM, need, personal health practices and use of services with OHRQoL in a simplified three-factor ABM showed T2DM had an impact on need, which in turn, had direct and indirect effects on OHRQoL. Need also influenced personal health practices and use of services, which in turn, had affected OHRQoL. Education and income also had effects on personal health practices and use of services.

Through all three Aims, we applied a theory-driven and practice-validated conceptual model with rigorous statistical techniques using a nationally representative in 
the US to analyze the association and pathways of T2DM and OHRQoL, including factors associated with these relationships. This research indicates that T2DM negatively affected OHRQoL in US adults. Risk factors of having poor OHRQoL (in descending order of importance) were current smoking, untreated dental caries, uncontrolled T2DM, unmet denture need, female gander, obesity, African American, periodontal disease. OHRQoL impairment protective factors were private dental insurance, college education, and annual dental prophylaxis. Importantly, need directly and indirectly influenced OHRQoL. Personal health practices and use of services also had affected OHRQoL.

\subsection{IMPLICATIONS FOR CLINICAL AND PRATICE}

Through all three Aims, the association between T2DM and poor OHRQoL was analyzed. In addition, factors that affected the relationship between T2DM and OHRQoL have the potential to inform regulatory policy on clinical practice and health policy research to improve oral population health for people with T2DM in the US were analyzed.

For public health practice, the findings indicate that T2DM plays an important role in the need for dental treatment, that in sequence affect personal health practices and OHRQoL (Aim 3). Preventable risk factors for impaired OHRQoL were uncontrolled T2DM, obesity, and smoking (Aim 2). Preventive programs need to encourage dentists to recommend that T2DM patients check HbA1c regularly, and before a dental visit. Health education programs should focus on people with uncontrolled T2DM, obesity, history of smoking, female gender, low income and less than a college education to help them understand adverse effects on these conditions on their oral health. ${ }^{3}$ Moreover, private dental insurance coverage and annual dental prophylaxis were preventive factors of poor 
OHRQoL (Aim 2). Health policy advocates focus more on policy for T2DM patients, especially females and those with low income and education. This vulnerable population needs affordable access to basic dental services (e.g., annual dental prophylaxis) and medical basic services (e.g., testing HbA1c, medication to control glycemia). In addition, perceived treatment need had the greatest effect on need for care and the reason for dental visits had the largest impact on personal health practices (Aim 3). Improved individual perception of oral care need and understanding benefits of regular dental check-ups are likely to improve OHRQoL. ${ }^{30}$ Health policymakers should support oral health preventive programs that educate T2DM individuals to improve their oral health attitudes (knowledge) and support dental benefits to include annual dental visits for this vulnerable population. Ultimately, Medicaid and Medicare programs should expand and include, respectively, routine dental care in their programs.

Clinically, dentists should advise their T2DM patients to check HbA1c at least four times a year to prevent uncontrolled diabetes, ${ }^{3}$ and explain adverse effects of untreated dental caries and periodontal disease on oral health, emphasizing that these conditions are preventable ${ }^{3,4}$ (Aim 2). Dentists should also encourage patients to have dental prophylaxis at least once a year (Aim 2). If patients have unmet dental needs, dentists should carefully explain the benefit of having a denture or other tooth replacement treatment to improve their quality of life. Perceived need had a greater effect than evaluated need on the requirement for oral care, which in turn affected personal health practices and use of services, indicating that patients' perception of dental treatment played an important role. Dentists should help patients appreciate the importance of oral health, especially for those with T2DM. Oral health professionals 
encourage patients to use preventive oral care regularly to prevent dental visits for serious oral problems. Although physical function had the greatest effect on OHRQoL, psychological and social functions effects were relatively close in magnitude to physical function (Aim 3). This finding indicates that dentists should pay more attention to psychological and social functions when they provide dental care. General medical health had an effect on need of oral care (Aim 3), indicating that dentists should advise patients to see a physician to assess for other medical conditions, in addition to T2DM. Physicians should advise T2DM patients to control their weight (for those with obesity), explain high risk of smoking cigarettes, and routinely have dental visits to check for oral disease (e.g., periodontal disease).,

\subsection{IMPLICATIONS FOR HEALTH POLICY RESEARCH}

Eight prior studies did not have control groups, used small sample sizes, variation in cut-off points used for binary logistic regression, and lack of theoretical basis to control for confounding factors (Aim 1). These shortcomings highlight the need for rigorous research design and methodology and better understanding how T2DM and oral conditions affect on OHRQoL. The current literature review highlights research gaps in understanding OHRQoL in patients with systemic conditions such as T2DM.

Our findings indicate that individuals with T2DM, a systemic disease, experienced lower OHRQoL. From the oral health perspective, T2DM patients are one of the vulnerable and underserved populations in the US national surveys (e.g., NHANES). Such surveys should routinely include OHRQoL to evaluate progress of improving the quality of life for all Americans. Researchers should collect more recent data to analyze the effects (e.g., cost benefit analysis) of providing access to basic oral care services (e.g., 
annual dental prophylaxis), medical preventive services (e.g., testing HbA1c), and health education (e.g., smoking control, weight control) on OHRQoL for T2DM patients. Oversampling of those with low income and less than a college education is needed. OHRQoL in patients with other systemic diseases (e.g., heart disease) are also vulnerable should be studied to provide evidence-based policymaking.

Given the advantages of SEM over traditional regression, the causal pathways of contextual factors associated with OHRQoL were simultaneously evaluated in the present study provide clinical and policy implications for clinicians, policymakers, and health policy researchers. SEM is not a panacea as it is only suitable for research problems in which direction of causality is intuitive. ${ }^{30,47}$ Future research should use SEM to help physicians, dentists and health policymakers better understand casual pathways between perceived oral health outcomes (OHRQoL) and other systemic diseases (e.g., heart disease), where appropriate to have proper treatments and policy for vulnerable populations.

Funding Disclosure: This project did not receive any financial support. Acknowledgement: The study in Chapter 3 was originally submitted to Community Dentistry and Oral Epidemiology (CDOE) on October 29 $9^{\text {th }}, 2019$ and got the decision of “major revisions" on December 30 ${ }^{\text {th }}$, 2019. It was re-submitted on March $12^{\text {th }}, 2020$ after revising the manuscript as suggested by the comments of the Editor in Chief and reviewers. As of April $1^{\text {st }}$, 2020, the manuscript of this study is under review at CDOE. Moreover, an abstract of this study was accepted to present as a poster on April 6, 2020 at the 2020 National Oral Health Conference in San Diego, CA. 


\section{REFERENCES}

1. Ogurtsova K, da Rocha Fernandes J, Huang Y, et al. IDF Diabetes Atlas: Global estimates for the prevalence of diabetes for 2015 and 2040. Diabetes Res Clin Pract. 2017;128:40-50.

2. Centers for Disease Control Prevention. National diabetes statistics report, 2017. 2017.

3. Verhulst MJ, Loos BG, Gerdes VE, Teeuw WJ. Evaluating all potential oral complications of diabetes mellitus. Front Endocrinol. 2019;10(56):1-49.

4. Tavares M, Calabi KAL, San Martin L. Systemic diseases and oral health. Dent Clin North Am. 2014;58(4):797-814.

5. Centers for Disease Control Prevention. Oral and Dental Health Fast Stats. 2018.

6. Wellapuli N, Ekanayake L. Association between chronic periodontitis and oral health-related quality of life in Sri Lankan adults. Int Dent J. 2016;66(6):337-343.

7. Allen E, Ziada H, O’halloran D, Clerehugh V, Allen P. Attitudes, awareness and oral health-related quality of life in patients with diabetes. J Oral Rehabil. 2008;35(3):218-223.

8. Passos-Soares JdS, Santos LPdS, Cruz SSd, et al. The impact of caries in combination with periodontitis on oral health-related quality of life in Bahia, Brazil. J Periodontol. 2018;89(12):1407-1417.

9. Nikbin A, Bayani M, Jenabian N, Motallebnejad M. Oral health-related quality of life in diabetic patients: comparison of the Persian version of Geriatric Oral 
Health Assessment Index and Oral Health Impact Profile: a descriptive-analytic study. J Diabetes Metab Disord. 2014;13(1):32.

10. Azogui-Lévy S, Dray-Spira R, Attal S, Hartemann A, Anagnostou F, Azerad J. Factors associated with oral health-related quality of life in patients with diabetes. Aust Dent J. 2018;63(2):163-169.

11. Sandberg GE, Wikblad KF. Oral health and health-related quality of life in type 2 diabetic patients and non-diabetic controls. Acta Odontol Scand. 2003;61(3):141148.

12. Furuta M, Yamashita Y. Oral health and swallowing problems. Curr Phys Med Rehabil Rep. 2013;1(4):216-222.

13. Locker D. Measuring oral health: a conceptual framework. Community Dent Health. 1988;5(1):3-18.

14. Al Shamrany M. Oral health-related quality of life: a broader perspective. East Mediterr Health J. 2006;12(6):894-901.

15. Bennadi D, Reddy C. Oral health related quality of life. J Int Soc Prev Community Dent. 2013;3(1):1-6.

16. Irani F, Wassall R, Preshaw P. Impact of periodontal status on oral health-related quality of life in patients with and without type 2 diabetes. $J$ Dent. 2015;43(5):506-511.

17. Shrivastava S, Naidu GS, Makkad RS, Nagi R, Jain S. Oral health related quality of life of controlled and uncontrolled type II diabetes mellitus patients-a questionnaire based comparative study. J Diabetes Metab Disord. 2018;14(2):2024. 
18. Sadeghi R, Taleghani F, Farhadi S. Oral health related quality of life in diabetic patients. J Dent Res Dent Clin Dent Prospects. 2014;8(4):230.

19. U.S. Department of Health and Human Services. Oral health in America: a report of the Surgeon General. Rockville, MD: U.S. Department of Health and Human Services, National Institute of Dental and Craniofacial Research, National Institutes of Health2000.

20. Naito M, Yuasa H, Nomura Y, Nakayama T, Hamajima N, Hanada N. Oral health status and health-related quality of life: a systematic review. J Oral Sci. 2006;48(1):1-7.

21. Gilbert GH, Duncan RP, Heft MW, Dolan TA, Vogel WB. Multidimensionality of oral health in dentate adults. Med Care. 1998;36(7):988-1001.

22. Inglehart MR, Bagramian R. Oral health-related quality of life. Quintessence Pub.; 2002.

23. Slade GD. Assessment of oral health related quality of life. Health Qual Life Outcomes. 2002;1(40):1-8.

24. Slade GD, Strauss RP, Atchison KA, Kressin NR, Locker D, Reisine ST. Conference summary: Assessing oral health outcomes - Measuring health status and quality of life. Community Dent Health. 1998;15(1):3-7.

25. Slade GD, Spencer AJ. Development and evaluation of the oral health impact profile. Community dental health. 1994;11(1):3-11.

26. Batra M, Aggarwal VP, Shah AF, Gupta M. Validation of Hindi version of oral health impact profile-14 for adults. J Indian Assoc Public Health Dent. 2015;13(4):469-474. 
27. Sanders AE, Slade GD, Lim S, Reisine ST. Impact of oral disease on quality of life in the US and Australian populations. Community Dent Oral Epidemiol. 2009;37(2):171-181.

28. Babitsch B, Gohl D, Von Lengerke T. Re-revisiting Andersen’s Behavioral Model of Health Services Use: a systematic review of studies from 1998-2011. Psychosoc Med. 2012;9(11):1-15.

29. Andersen RM. Revisiting the behavioral model and access to medical care: does it matter? J Health Soc Behav. 1995;36(1):1-10.

30. Baker S. Applying Andersen's behavioural model to oral health: what are the contextual factors shaping perceived oral health outcomes? Community Dent Oral Epidemiol. 2009;37(6):485-494.

31. de Pinho AMS, Borges CM, de Abreu MHNG, Vargas AMD. Impact of periodontal disease on the quality of life of diabetics based on different clinical diagnostic criteria. Int J Dent. 2012;2012(986412):1-8.

32. Cortelli SC, Costa FO, Gargioni-Filho A, et al. Impact of gingivitis treatment for diabetic patients on quality of life related to periodontal objective parameters: a randomized controlled clinical trial. Arch Oral Biol. 2018;86(2):80-86.

33. Mourão LC, Garcia E, Passos D, Lorena T, Canabarro A. Impact of wellcontrolled type 2 diabetes mellitus on quality of life of chronic periodontitis patients. J Indian Soc Periodontol. 2016;20(6):623-626.

34. Mohsin SF, Fawwad A, Mustafa N, Shoaib A, Basit A. Impact of type 2 diabetes mellitus on oral health related quality of life among adults in Karachi, Pakistan - a cross-sectional study. Qual Life Res. 2017;20(1):1-7. 
35. Pinho RCM, de Melo Dias RSA, Bandeira F, da Silva Barbosa AC, Júnior AdFC, Cimões RJHSJ. Impact of Chronic Periodontitis on the Quality of Life of Individuals with and without Diabetes. 2018;12(2):1-11.

36. de Sousa RV, Pinho RCM, Vajgel BdCF, de Paiva SM, Cimões R. Evaluation of oral health-related quality of life in individuals with type 2 diabetes mellitus. Braz J Oral Sci. 2019;18:e191431-e191431.

37. Moher D, Shamseer L, Clarke M, et al. Preferred reporting items for systematic review and meta-analysis protocols (PRISMA-P) 2015 statement. Syst Rev. 2015;4(1):1.

38. Mohamed HG, Idris SB, Ahmed MF, et al. Association between oral health status and type 2 diabetes mellitus among Sudanese adults: a matched case-control study. PLoS One. 2013;8(12):e82158.

39. Mohamed HG, Mustafa K, Ibrahim SO, Åstrøm ANJH, outcomes qol. Dietary habits, oral impact on daily performance and type 2 diabetes: a matched casecontrol study from Sudan. Health Qual Life Outcomes. 2017;15(1):111.

40. Tsai C, Hayes C, Taylor GW. Glycemic control of type 2 diabetes and severe periodontal disease in the US adult population. Community Dent Oral Epidemiol. 2002;30(3):182-192.

41. Maida CA, Marcus M, Spolsky VW, Wang Y, Liu H. Socio-behavioral predictors of self-reported oral health-related quality of life. Qual Life Res. 2013;22(3):559566. 
42. Huang DL, Park M. Socioeconomic and racial/ethnic oral health disparities among US older adults: oral health quality of life and dentition. J Public Health Dent. 2015;75(2):85-92.

43. Seirawan H, Sundaresan S, Mulligan R. Oral health-related quality of life and perceived dental needs in the United States. J Public Health Dent. 2011;71(3):194-201.

44. Walter MH, Schuette U, Raedel M, et al. Oral health-related quality of life and oral status in a German working population. Eur J Oral Sci. 2011;119(6):481-488.

45. Walter MH, Woronuk JI, Tan H-K, et al. Determinants of oral health-related quality of life in a cross-cultural German-Canadian sample. J Public Health. 2007;15(1):43-50.

46. Stancil TR, Li CH, Hyman JJ, Reid BC, Reichman ME. Dental insurance and clinical dental outcomes in NHANES III. J Public Health Dent. 2005;65(4):189195.

47. Baker SR, Pearson NK, Robinson PG. Testing the applicability of a conceptual model of oral health in housebound edentulous older people. Community Dent Oral Epidemiol. 2008;36(3):237-248.

48. Tomar SL, Asma S. Smoking-attributable periodontitis in the United States: findings from NHANES III. J Periodontol. 2000;71(5):743-751.

49. Meyers LS, Gamst G, Guarino AJ. Applied multivariate research: Design and interpretation. Sage publications; 2016.

50. Ajzen I. The theory of planned behaviour: reactions and reflections. Psychol Health. 2011;26(9):1113-1127. 
Table 2.1. Data extracted from reviewed studies without control group

\begin{tabular}{|c|c|c|c|c|c|c|c|c|}
\hline Year & $\begin{array}{l}\text { Author } \\
\text { (country) }\end{array}$ & Design & $\begin{array}{l}\text { Statistical } \\
\text { analysis }\end{array}$ & $\begin{array}{l}\text { Sample } \\
\text { size }\end{array}$ & $\begin{array}{l}\text { Age } \\
\text { range }\end{array}$ & $\begin{array}{l}\text { OHRQoL } \\
\text { measures }\end{array}$ & T2DM & $\begin{array}{l}\text { Key findings } \\
\text { (significant } \\
\text { covariates) }\end{array}$ \\
\hline 2019 & $\begin{array}{l}\text { de Sousa et } \\
\text { al (Brazil) })^{3}\end{array}$ & $\begin{array}{l}\text { Population- } \\
\text { based } \\
\text { cross- } \\
\text { sectional }\end{array}$ & $\begin{array}{l}\text { Multivariate } \\
\text { logistic } \\
\text { regression } \\
\text { (forward } \\
\text { stepwise) }\end{array}$ & $\begin{array}{l}N=302 \\
(T 2 D M)\end{array}$ & $\begin{array}{l}\text { Mean } \\
\text { age = } \\
63.1 \\
\text { years }\end{array}$ & $\begin{array}{l}\text { OHIP-14 } \\
\text { (Brazilian) } \\
\text { OHIP-SC } \\
\text { (sometimes/of } \\
\text { ten/very often) }\end{array}$ & $\begin{array}{l}\text { Significance of } \\
\text { T2DM and } \\
\text { OHRQoL was } \\
\text { not reported. } \\
\text { (T2DM defined } \\
\text { as fasting } \\
\text { blood glucose } \geq \\
126 \text { or glycated } \\
\text { hemoglobin }> \\
6.5 \% \text { ) }\end{array}$ & $\begin{array}{l}\text { o Xerostomia } \\
\text { o Denture need } \\
\text { o Periodontitis } \\
\text { (Not controlled } \\
\text { for } \\
\text { socioeconomic } \\
\text { factors) }\end{array}$ \\
\hline 2018 & $\begin{array}{l}\text { Passos- } \\
\text { Soares et al } \\
\text { (Brazil) }^{6}\end{array}$ & $\begin{array}{l}\text { Cross- } \\
\text { sectional }\end{array}$ & $\begin{array}{l}\text { - Poisson } \\
\text { regression } \\
\text { - Logistic } \\
\text { regression }\end{array}$ & $\begin{array}{l}\mathrm{N}=306 \\
\text { (with } \\
\text { diabetes) }\end{array}$ & $\begin{array}{l}18-80 \\
\text { years }\end{array}$ & $\begin{array}{l}\text { OHIP-14 } \\
\text { (Brazilian) } \\
\text { OHIP-ADD as } \\
\text { a continuous } \\
\text { covariate }\end{array}$ & $\begin{array}{l}\text { Association } \\
\text { between } \\
\text { diabetes and } \\
\text { OHRQoL was } \\
\text { not significant. }\end{array}$ & $\begin{array}{l}\text { - Both dental caries } \\
\text { and periodontitis } \\
\text { - Age } \\
\text { - Sex } \\
\text { - Schooling level } \\
\text { - Smoking habit }\end{array}$ \\
\hline 2018 & $\begin{array}{l}\text { Shrivastava } \\
\text { et al } \\
\text { (India) }^{12}\end{array}$ & $\begin{array}{l}\text { Cross- } \\
\text { sectional }\end{array}$ & $\begin{array}{l}\text { - Student } t \text { test } \\
\text { - Pearson’s } \\
\text { correlation }\end{array}$ & $\begin{array}{l}\mathrm{N}=110 \\
\text { (with } \\
\text { T2DM) }\end{array}$ & $\begin{array}{l}\text { Age was } \\
\text { not } \\
\text { reported }\end{array}$ & $\begin{array}{l}\text { GOHAI } \\
\text { OHIP-14 } \\
\text { (ADD) as } \\
\text { continuous } \\
\text { outcomes }\end{array}$ & $\begin{array}{l}\text { Significantly } \\
\text { worse in } \\
\text { uncontrol } \\
\text { T2DM group } \\
\text { (HbA1c }>8 \text {, } \\
n=53) \\
\text { compared to } \\
\text { control group } \\
(n=57)\end{array}$ & $\begin{array}{l}\text { Compare to } \\
\text { controlled T2DM } \\
\text { group, participants } \\
\text { with uncontrolled } \\
\text { T2DM had more } \\
\text { impacts on } \\
\text { o chewing } \\
\text { o swallowing } \\
\text { o speaking } \\
\text { o eating }\end{array}$ \\
\hline
\end{tabular}




\begin{tabular}{|c|c|c|c|c|c|c|c|c|}
\hline 2017 & $\begin{array}{l}\text { Mohsin et } \\
\text { al } \\
\text { (Pakistan) }^{9}\end{array}$ & $\begin{array}{l}\text { Cross- } \\
\text { section }\end{array}$ & $\begin{array}{l}\text { - ANOVA } \\
\text { analysis } \\
\text { - Kendall's } \\
\text { Tau-b } \\
\text { - Mann- } \\
\text { Whitney }\end{array}$ & $\begin{array}{l}\mathrm{N}=101 \\
\text { (with } \\
\mathrm{T} 2 \mathrm{DM} \text { ) }\end{array}$ & $\begin{array}{l}\geq 30 \\
\text { years } \\
\text { (mean } \\
=53.3 \\
\text { years) }\end{array}$ & $\begin{array}{l}\text { OHIP-14 } \\
\text { OHIP-ADD as } \\
\text { a continuous } \\
\text { outcome }\end{array}$ & $\begin{array}{l}\text { Significance of } \\
\text { T2DM and } \\
\text { OHRQoL was } \\
\text { not reported. }\end{array}$ & $\begin{array}{l}\text { - No significant } \\
\text { correlation between } \\
\text { glycemic control } \\
\text { and OHIP }\end{array}$ \\
\hline 2014 & $\begin{array}{l}\text { Nikbin et } \\
\text { al (Iran) }{ }^{11}\end{array}$ & $\begin{array}{l}\text { Cross- } \\
\text { sectional }\end{array}$ & $\begin{array}{l}\text { Logistic } \\
\text { regression }\end{array}$ & $\begin{array}{l}\mathrm{N}=350 \\
\text { (with } \\
\mathrm{T} 2 \mathrm{DM} \text { ) }\end{array}$ & $\begin{array}{l}22-86 \\
\text { years } \\
\text { (mean } \\
=55 \text { ) }\end{array}$ & $\begin{array}{l}\text { Persian OHIP- } \\
14 \\
\text { GOHAI } \\
\text { (ADD and } \\
\text { SC) } 25^{\text {th }} \text { cutoff }\end{array}$ & $\begin{array}{l}\text { Significance of } \\
\text { T2DM and } \\
\text { OHRQoL was } \\
\text { not reported. }\end{array}$ & $\begin{array}{l}\text { - Xerostomia } \\
\text { - Type of antibiotic } \\
\text { medication }\end{array}$ \\
\hline 2014 & $\begin{array}{l}\text { Sadeghi et } \\
\text { al (Iran) }^{7}\end{array}$ & $\begin{array}{l}\text { Cross- } \\
\text { sectional }\end{array}$ & $\begin{array}{l}\text { Logistic } \\
\text { regression }\end{array}$ & $\begin{array}{l}\mathrm{N}=200 \\
\text { (with } \\
\text { diabetes) }\end{array}$ & $\begin{array}{l}\text { Mean } \\
=55.2 \\
\text { years }\end{array}$ & $\begin{array}{l}\text { OHIP-20 } \\
\text { OHIP-ADD } \\
\text { (cutoff } 60 \text { for } \\
\text { range 20-100) }\end{array}$ & $\begin{array}{l}\text { Association } \\
\text { between } \\
\text { diabetes and } \\
\text { OHRQoL was } \\
\text { not significant. } \\
\text { (type 1, type 2) } \\
\text { (controlled } \\
\text { diabetes } \\
\text { defined as } \\
\text { HbA1c < 8\%) }\end{array}$ & $\begin{array}{l}\text { - Age } \\
\text { - Knowledge of } \\
\text { complications } \\
\text { - Dental referral by } \\
\text { physician } \\
\text { - frequency of } \\
\text { brushing } \\
\text { - length of time } \\
\text { diagnosed with } \\
\text { diabetes }\end{array}$ \\
\hline 2012 & $\begin{array}{l}\text { de Pinho et } \\
\text { al (Brazil) }\end{array}$ & $\begin{array}{l}\text { Population- } \\
\text { based } \\
\text { cross- } \\
\text { sectional }\end{array}$ & $\begin{array}{l}\text { - Man- } \\
\text { Whitney } \\
\text { - Kruskall } \\
\text { Wallis } \\
\text { - Pearson chi- } \\
\text { square }\end{array}$ & $\begin{array}{l}\mathrm{N}=300 \\
\text { (with } \\
\text { diabetes) }\end{array}$ & $\begin{array}{l}30-54 \\
49.3 \% \\
\geq 55 \\
50.7 \%\end{array}$ & $\begin{array}{l}\text { OHIP-14 } \\
\text { Binary } \\
\text { outcome for } \\
\text { impact on } 4 \\
\text { dimensions } \\
\text { (never vs } \\
\text { sometimes/al } \\
\text { ways) }\end{array}$ & $\begin{array}{l}\text { Significance of } \\
\text { diabetes and } \\
\text { OHRQoL was } \\
\text { not reported. } \\
\text { 28.7\% Type } 1 \\
71.3 \% \text { Type } 2\end{array}$ & $\begin{array}{l}\text { - Periodontitis } \\
\text { (different clinical } \\
\text { diagnostic criteria) } \\
\text { - Limitations on } \\
\text { different } \\
\text { dimensions: } \\
\text { o Psychological } \\
\text { o Physical } \\
\text { o Handicap } \\
\text { o Pain } \\
\text { o Functional }\end{array}$ \\
\hline
\end{tabular}




\begin{tabular}{|c|c|c|c|c|c|c|c|c|}
\hline 2008 & $\begin{array}{l}\text { Allen et al } \\
(\mathrm{UK})^{4}\end{array}$ & $\begin{array}{l}\text { Cross- } \\
\text { sectional }\end{array}$ & $\begin{array}{l}\text { - Chi-squared } \\
\text { test } \\
\text { - Pearson } \\
\text { correlation }\end{array}$ & $\begin{array}{l}\mathrm{N}=101 \\
\text { (with } \\
\text { diabetes) }\end{array}$ & $\begin{array}{l}31-79 \\
\text { (mean } \\
=56)\end{array}$ & $\begin{array}{l}\text { OHIP-20 } \\
\text { OHIP-SC } \\
\text { (always/somet } \\
\text { imes) }\end{array}$ & $\begin{array}{l}\text { - Significance } \\
\text { of diabetes and } \\
\text { OHRQoL was } \\
\text { not reported. } \\
\text { - 27\% Type } 1 \text {, } \\
66 \% \text { Type } 2 \text {, } \\
7 \% \text { unknown } \\
\text { - HbA1c } \\
\text { control: 6.2, 9, } \\
12 \text { (mean } 8.2 \text { ). } \\
\text { Moderate to } \\
\text { poor } 7.5\end{array}$ & $\begin{array}{l}\text { - Attitude of } \\
\text { o periodontitis } \\
\text { o heart disease } \\
\text { o eye disease } \\
\text { o circulatory } \\
\text { problem } \\
\text { o kidney disease } \\
\text { - Dentate status } \\
\text { - Attend dentist last } \\
\text { year, } 5 \text { years }\end{array}$ \\
\hline
\end{tabular}


Table 2.2. Data extracted from reviewed studies with control group

\begin{tabular}{|c|c|c|c|c|c|c|c|c|}
\hline Year & $\begin{array}{l}\text { Author } \\
\text { (country) }\end{array}$ & Design & $\begin{array}{c}\text { Statistical } \\
\text { analysis }\end{array}$ & $\begin{array}{l}\text { Sample } \\
\text { size }\end{array}$ & $\begin{array}{l}\text { Age } \\
\text { range }\end{array}$ & $\begin{array}{l}\text { OHRQoL } \\
\text { measures }\end{array}$ & T2DM & $\begin{array}{c}\text { Key findings } \\
\text { (significant covariates) }\end{array}$ \\
\hline 2018 & $\begin{array}{l}\text { Pinho et al } \\
\text { (Brazil) }^{2}\end{array}$ & $\begin{array}{l}\text { Case- } \\
\text { control }\end{array}$ & $\begin{array}{l}\text { Binary } \\
\text { logistic } \\
\text { regression }\end{array}$ & $\begin{array}{l}\mathrm{N}=280 \\
(116 \mathrm{~T} 2 \mathrm{DM}, \\
164 \text { no } \\
\text { T2DM) }\end{array}$ & $\begin{array}{l}20-80 \\
\text { years }\end{array}$ & $\begin{array}{l}\text { OHIP-14 } \\
\text { (Brazilian) } \\
\text { OHIP-SC }\end{array}$ & $\begin{array}{l}\text { Significance of } \\
\text { T2DM was not } \\
\text { reported }\end{array}$ & $\begin{array}{l}\text { Among participants with } \\
\text { both T2DM and chronic } \\
\text { periodontitis: } \\
\text { o Female } \\
\text { o Higher visible plaque } \\
\text { index } \\
\text { o Fewer number of teeth }\end{array}$ \\
\hline 2017 & $\begin{array}{l}\text { Azogui- } \\
\text { Lévy et al } \\
\text { (France) }^{10}\end{array}$ & $\begin{array}{l}\text { Cross } \\
\text { sectional }\end{array}$ & $\begin{array}{l}\text { Binary } \\
\text { Logistic } \\
\text { regression }\end{array}$ & $\begin{array}{l}\mathrm{N}=316 \\
(148 \\
\text { diabetes, } \\
168 \text { no } \\
\text { diabetes) }\end{array}$ & $\begin{array}{l}\geq 18 \text { years } \\
\text { (mean }= \\
57 \text { years) }\end{array}$ & GOHAI & $\begin{array}{l}\text { Significant } \\
\text { association with } \\
\text { T2DM } \\
\text { 37.3\% Type } 1 \\
\text { 61.7\% Type } 2\end{array}$ & $\begin{array}{l}\text { - Poor oral health (have at } \\
\text { least one missing tooth } \\
\text { and not replaced, bleed } \\
\text { during brushing and have } \\
\text { abscess last year) } \\
\text { - Dry mouth } \\
\text { - Wear removable denture }\end{array}$ \\
\hline 2017 & $\begin{array}{l}\text { Mohamed } \\
\text { et al } \\
\text { (Sudan) }^{14}\end{array}$ & $\begin{array}{l}\text { Matched } \\
\text { case- } \\
\text { control }\end{array}$ & $\begin{array}{l}\text { Logistic } \\
\text { regression }\end{array}$ & $\begin{array}{l}\mathrm{N}=447 \\
(149 \text { T2DM, } \\
298 \text { no } \\
\text { T2DM) }\end{array}$ & $\begin{array}{l}24-70 \\
\text { years } \\
(\text { mean = } \\
52.3 \\
\text { years) }\end{array}$ & OIDP & $\begin{array}{l}\text { Significance of } \\
\text { diabetes and } \\
\text { OHRQoL was } \\
\text { not reported } \\
\text { (T2DM status } \\
\text { was a covariate) }\end{array}$ & $\begin{array}{l}\text { - Consumption of } \\
\text { o meat } \\
\text { o bread } \\
\text { - Adjusted for dental } \\
\text { plaque index, bleeding on } \\
\text { probing, tooth mobility, } \\
\text { root caries, periodontal } \\
\text { probing, depth and } \\
\text { missing teeth (no } p \text { values } \\
\text { reported) }\end{array}$ \\
\hline
\end{tabular}




\begin{tabular}{|c|c|c|c|c|c|c|c|c|}
\hline 2017 & $\begin{array}{l}\text { Cortelli et } \\
\text { al } \\
\left(_{\text {Brazil })^{16}}\right.\end{array}$ & $\begin{array}{l}\text { Longitud } \\
\text { inal study } \\
\text { (3 } \\
\text { months) }\end{array}$ & $\begin{array}{l}\text { Linear } \\
\text { regression }\end{array}$ & $\begin{array}{l}\mathrm{N}=105 \\
(53 \text { no } \\
\text { T2DM, } 52 \\
\text { T2DM: } 24 \\
\text { with } \\
\text { mouthwash, } \\
28 \text { without } \\
\text { mouthwash) }\end{array}$ & $\begin{array}{l}20-45 \\
\text { years } \\
\text { (mean = } \\
32 \text { years) }\end{array}$ & $\begin{array}{l}\text { OHQoL- } \\
\text { UK }\end{array}$ & $\begin{array}{l}\text { - Significance of } \\
\text { T2DM was not } \\
\text { reported } \\
\text { (T2DM status } \\
\text { was a covariate) }\end{array}$ & $\begin{array}{l}\text { - Essential-oil } \\
\text { mouthwash to lower } \\
\text { plaque, gingival indices, } \\
\text { levels of bacteria } \\
\text { - Periodontitis had an } \\
\text { impact on OHRQoL in } \\
\text { T2DM, but not in patients } \\
\text { without T2DM }\end{array}$ \\
\hline 2016 & $\begin{array}{l}\text { Mourão et } \\
\text { al } \\
\left(_{\text {Brazil })^{17}}\right.\end{array}$ & $\begin{array}{l}\text { Matched } \\
\text { cross- } \\
\text { sectional } \\
\text { case- } \\
\text { controlle } \\
\text { d }\end{array}$ & $\begin{array}{l}\text { Kolmogor } \\
\text { ov- } \\
\text { Smirnov, } \\
\text { Paired t- } \\
\text { test, } \chi^{2} \text {, } \\
\text { Wilcoxon }\end{array}$ & $\begin{array}{l}\mathrm{N}=500(250 \\
\mathrm{T} 2 \mathrm{DM}, 250 \\
\text { no T2DM })\end{array}$ & $\begin{array}{l}\text { Age 30-76 } \\
\text { years }\end{array}$ & $\begin{array}{l}\text { FACIT-F } \\
\text { (Portugues } \\
\text { e) }\end{array}$ & $\begin{array}{l}\text { Significant } \\
\text { association of } \\
\text { T2DM and QoL } \\
\text { Only well- } \\
\text { controlled } \\
\text { (HbA1c } \leq 8 \%) \\
\text { T2DM included }\end{array}$ & $\begin{array}{l}\text { Bivariate analysis with } \\
\text { significant difference } \\
\text { o clinical attachment } \\
\text { loss, probing pocket } \\
\text { depth, fasting glucose, } \\
\text { extension of chronic } \\
\text { periodontitis } \\
\text { o QoL dimensions } \\
\text { (physical, social, } \\
\text { functional, limitation) }\end{array}$ \\
\hline 2016 & $\begin{array}{l}\text { Wellapuli } \\
\text { et al (Sri } \\
\text { Lanka) }\end{array}$ & $\begin{array}{l}\text { Populatio } \\
\text { n-based } \\
\text { cross- } \\
\text { sectional }\end{array}$ & $\begin{array}{l}\text { Poisson } \\
\text { regression }\end{array}$ & $\begin{array}{l}\mathrm{N}=1400 \\
\text { (with and } \\
\text { without } \\
\text { diabetes) }\end{array}$ & $\begin{array}{l}35-60 \\
\text { years } \\
(\text { mean }= \\
43.5 \\
\text { years) }\end{array}$ & $\begin{array}{l}\text { OHIP-14 } \\
\text { (Malaysia } \\
\text { n, Sinhala, } \\
\text { Tamil) } \\
\text { OHIP-SC } \\
\text { (fairly/ver } \\
\text { y often) }\end{array}$ & $\begin{array}{l}\text { No significant } \\
\text { difference by } \\
\text { diabetes (self- } \\
\text { reported) }\end{array}$ & $\begin{array}{l}\text { - Chronic periodontitis } \\
\text { (moderate, severe) } \\
\text { - Current smoking } \\
\text { - Education }(11-13,>13) \\
\text { - Sex }\end{array}$ \\
\hline
\end{tabular}




\begin{tabular}{|c|c|c|c|c|c|c|c|c|}
\hline 2013 & $\begin{array}{l}\text { Mohamed } \\
\text { et al } \\
\text { (Sudan) }^{13}\end{array}$ & $\begin{array}{l}\text { Matched } \\
\text { case- } \\
\text { control }\end{array}$ & $\begin{array}{l}\text { Logistic } \\
\text { regression }\end{array}$ & $\begin{array}{l}\mathrm{N}=457 \\
(154 \mathrm{~T} 2 \mathrm{DM}, \\
303 \text { no } \\
\text { T2DM) }\end{array}$ & $\begin{array}{l}\text { Mean age } \\
\text { of T2DM } \\
=52.6 \\
\text { years } \\
\text { Mean age } \\
\text { of no } \\
\text { T2DM = } \\
52.4 \text { years }\end{array}$ & $\begin{array}{l}\text { OIDP } \\
\text { (English } \\
\text { questionna } \\
\text { ire, } \\
\text { interviewe } \\
\text { d in } \\
\text { Arabic) }\end{array}$ & $\begin{array}{l}\text { Significant } \\
\text { association with } \\
\text { T2DM } \\
\text { T2DM is the } \\
\text { main outcome } \\
\text { (Controlled } \\
\text { T2DM defined as } \\
\text { HbA1c } \leq 8 \text {, } \\
\text { uncontrolled as } \\
\text { HbA1c }>8 \% \text { ) }\end{array}$ & $\begin{array}{l}\text { - Periodontitis } \\
\text { - Controlled for } \\
\text { o age } \\
\text { o gender } \\
\text { o dental attendance } \\
\text { - Study variables } \\
\text { o probing depths } \\
\text { o furcation involvement } \\
\text { o tooth mobility } \\
\text { o missing teeth } \\
\text { - Poorly controlled } \\
\text { T2DM } \\
\text { o higher level of mobility } \\
\text { index } \\
\text { - Long duration of T2DM } \\
\text { higher decayed, missed, } \\
\text { filled teeth (DMFT) } \\
\text { values }\end{array}$ \\
\hline 2003 & $\begin{array}{l}\text { Sandberg } \\
\text { et al } \\
(\text { Sweden })^{1} \\
5\end{array}$ & $\begin{array}{l}\text { Matched } \\
\text { cross } \\
\text { sectional }\end{array}$ & $\begin{array}{l}\text { Linear } \\
\text { regression }\end{array}$ & $\begin{array}{l}\mathrm{N}=204 \\
(102 \mathrm{~T} 2 \mathrm{DM}, \\
102 \text { no } \\
\text { T2DM })\end{array}$ & $\begin{array}{l}\text { Age } \leq 75 \\
\text { years } \\
\text { (mean age } \\
\text { of T2DM } \\
=64.8 \\
\text { years, } \\
\text { mean age } \\
\text { of no } \\
\text { T2DM = } \\
64.9 \\
\text { years) }\end{array}$ & $\begin{array}{l}\text { SF-36 } \\
\text { (HRQoL) } \\
\text { with } 8 \\
\text { domains }\end{array}$ & $\begin{array}{l}\text { Significance of } \\
\text { T2DM was not } \\
\text { reported } \\
\text { (Controlled } \\
\text { T2DM defined as } \\
\text { HbA1c } \leq 7.5 \text {, } \\
\text { uncontrolled as } \\
\text { HbA1c }>7.5 \% \text { ) }\end{array}$ & $\begin{array}{l}\text { T2DM played an } \\
\text { important role in physical } \\
\text { functioning and social } \\
\text { functioning of OHRQoL, } \\
\text { general health (with no } p \\
\text { values and correlation } \\
\text { reported). }\end{array}$ \\
\hline
\end{tabular}


Table 3.1. Demographics and potential risk factors associated with OHRQoL in US adults with and without diabetes according to OHIP-ADD and OHIP-SC cutoff values

\begin{tabular}{|c|c|c|c|c|c|c|}
\hline & \multicolumn{3}{|c|}{$\begin{array}{c}\text { Severity Scores } \\
\text { (OHIP-ADD) }\end{array}$} & \multicolumn{3}{|c|}{$\begin{array}{l}\text { Prevalence } \\
\text { (OHIP-SC) }\end{array}$} \\
\hline & Mean (SE) & Effect $^{\mathbf{a}}$ & $p$ value & Proportion (SE) & Effect $^{\mathbf{a}}$ & $p$ value \\
\hline All & $2.65(0.10)$ & & & $14.17 \quad(0.88)$ & & \\
\hline \multicolumn{7}{|l|}{ Need factors } \\
\hline T2DM & & & 0.007 & & & $<0.001$ \\
\hline No & $2.58(0.10)$ & Ref & & $13.57 \quad(0.97)$ & Ref & \\
\hline Yes with HbA1c < 8\% & $3.20(0.34)$ & $24 \%$ & & $18.79 \quad(2.42)$ & $38 \%$ & \\
\hline Yes with $\mathrm{HbA} 1 \mathrm{c} \geq 8 \%$ & $4.20(0.63)$ & $63 \%$ & & $26.44 \quad(4.15)$ & $95 \%$ & \\
\hline Obesity & & & 0.029 & & & 0.070 \\
\hline $\mathrm{BMI}<30 \mathrm{~kg} / \mathrm{m} 2$ & $2.51(0.09)$ & Ref & & $12.82 \quad(0.96)$ & Ref & \\
\hline $\mathrm{BMI} \geq 30 \mathrm{~kg} / \mathrm{m} 2$ & $2.96(0.20)$ & $18 \%$ & & $17.07 \quad(2.01)$ & $33 \%$ & \\
\hline Untreated dental caries & & & $<0.001$ & & & $<0.001$ \\
\hline No & $2.30(0.07)$ & Ref & & $11.59 \quad(0.84)$ & Ref & \\
\hline Yes & $3.78(0.28)$ & $64 \%$ & & $22.34 \quad(1.18)$ & $93 \%$ & \\
\hline Periodontal diseases & & & 0.008 & & & 0.026 \\
\hline No & $2.51(0.08)$ & Ref & & $13.52 \quad(0.78)$ & Ref & \\
\hline Yes & $3.66(0.41)$ & $46 \%$ & & $18.72 \quad(2.58)$ & $38 \%$ & \\
\hline Unmet denture need & & & 0.048 & & & 0.102 \\
\hline No & $2.62(0.11)$ & Ref & & $14.00 \quad(0.95)$ & Ref & \\
\hline Yes & $4.14(0.63)$ & $58 \%$ & & $23.70 \quad(5.67)$ & $69 \%$ & \\
\hline \multicolumn{7}{|l|}{ Enabling factors } \\
\hline Income & & & 0.003 & & & 0.005 \\
\hline$<200 \%$ FPL & $2.34(0.07)$ & Ref & & $12.25 \quad(0.83)$ & Ref & \\
\hline$\geq 200 \%$ FPL & $3.41(0.30)$ & $46 \%$ & & $18.90 \quad(2.12)$ & $54 \%$ & \\
\hline
\end{tabular}




\begin{tabular}{|c|c|c|c|c|c|c|}
\hline Private dental insurance & & & 0.053 & & & 0.019 \\
\hline No & $2.90(0.19)$ & Ref & & (1.12) & Ref & \\
\hline Yes & $2.46(0.10)$ & $-15 \%$ & & $12.27 \quad(1.26)$ & $-26 \%$ & \\
\hline Education & & & 0.023 & & & \\
\hline High school and below & $3.04(0.23)$ & Ref & & 17.54 (1.76) & Ref & \\
\hline College and above & $2.40(0.09)$ & $-21 \%$ & & $11.98 \quad(1.01)$ & $-32 \%$ & \\
\hline \multicolumn{7}{|l|}{ Predisposing factors } \\
\hline Sex & & & 0.036 & & & 0.005 \\
\hline Male & $2.42(0.14)$ & Ref & & $11.50 \quad(1.01)$ & Ref & \\
\hline Female & $2.87(0.15)$ & $19 \%$ & & $16.64 \quad(1.31)$ & $45 \%$ & \\
\hline Race/ethnicity & & & 0.009 & & & $<0.001$ \\
\hline White, Latino & $2.59(0.09)$ & Ref & & $13.62 \quad(0.83)$ & Ref & \\
\hline African American & $3.29(0.27)$ & $27 \%$ & & $19.41 \quad(1.45)$ & $43 \%$ & \\
\hline Age in years $(48.5 \pm 16.8)$ & & & 0.090 & & & 0.889 \\
\hline$<45$ & $2.72(0.17)$ & Ref & & $13.24 \quad(1.18)$ & Ref & \\
\hline $45-64$ & $2.86(0.17)$ & $5 \%$ & & $16.63 \quad(1.82)$ & $26 \%$ & \\
\hline$\geq 65$ & $2.14(0.12)$ & $-21 \%$ & & $11.81 \quad(1.12)$ & $-11 \%$ & \\
\hline Tobacco smoking & & & $<0.001$ & & & $<0.001$ \\
\hline Never smoker & $2.30(0.11)$ & Ref & & $11.47 \quad(0.70)$ & Ref & \\
\hline Former smoker & $2.40(0.13)$ & $4 \%$ & & $12.01 \quad(1.41)$ & $5 \%$ & \\
\hline Current smoker & $3.78(0.25)$ & $64 \%$ & & $23.17 \quad(2.45)$ & $102 \%$ & \\
\hline Annual dental prophylaxis & & & $<0.001$ & & & 0.002 \\
\hline No & $3.18(0.16)$ & Ref & & $(1.14)$ & Ref & \\
\hline Yes & $2.28(0.10)$ & $-28 \%$ & & $(1.15)$ & $-34 \%$ & \\
\hline
\end{tabular}


Table 3.2. Bivariate analysis of participant's characteristics by T2DM status

\begin{tabular}{|c|c|c|c|c|c|}
\hline \multirow{5}{*}{ Variable } & \multirow{3}{*}{ Total } & \multicolumn{3}{|c|}{ T2DM } & \multirow{5}{*}{$p$ value } \\
\hline & & \multirow{2}{*}{ No } & \multicolumn{2}{|c|}{ Yes } & \\
\hline & & & Controlled & Uncontrolled & \\
\hline & $\mathrm{N}=131,397,654$ & $\mathrm{~N}=119,977,457$ & $\mathrm{~N}=8,878,465$ & $\mathrm{~N}=2,541,732$ & \\
\hline & $(100 \%)$ & $(91.3 \%)$ & $(6.8 \%)$ & $(1.9 \%)$ & \\
\hline Oral health outcomes & & & & & \\
\hline OHIP-ADD & & & & & $<0.0001$ \\
\hline OHIP-ADD < 6 (ref.) & $83.2 \%$ & $83.7 \%$ & $79.4 \%$ & $74.7 \%$ & \\
\hline OHIP-ADD $\geq 6$ & $16.8 \%$ & $16.3 \%$ & $20.6 \%$ & $25.3 \%$ & \\
\hline OHIP-SC & & & & & $<0.0001$ \\
\hline OHIP-SC = 0 (ref.) & $85.8 \%$ & $86.4 \%$ & $81.2 \%$ & $73.6 \%$ & \\
\hline OHIP-SC $>0$ & $14.2 \%$ & $13.6 \%$ & $18.8 \%$ & $26.4 \%$ & \\
\hline \multicolumn{6}{|l|}{ Need factors } \\
\hline Obesity & & & & & $<0.0001$ \\
\hline BMI < 30 kg/m2 (ref.) & $68.2 \%$ & $70.5 \%$ & $41.2 \%$ & $50.5 \%$ & \\
\hline $\mathrm{BMI} \geq 30 \mathrm{~kg} / \mathrm{m} 2$ & $31.8 \%$ & $29.5 \%$ & $58.8 \%$ & $49.5 \%$ & \\
\hline Untreated dental caries & & & & & $<0.0001$ \\
\hline No (ref.) & $76.0 \%$ & $75.9 \%$ & $78.4 \%$ & $73.1 \%$ & \\
\hline Yes & $24.0 \%$ & $25.1 \%$ & $21.6 \%$ & $26.9 \%$ & \\
\hline
\end{tabular}




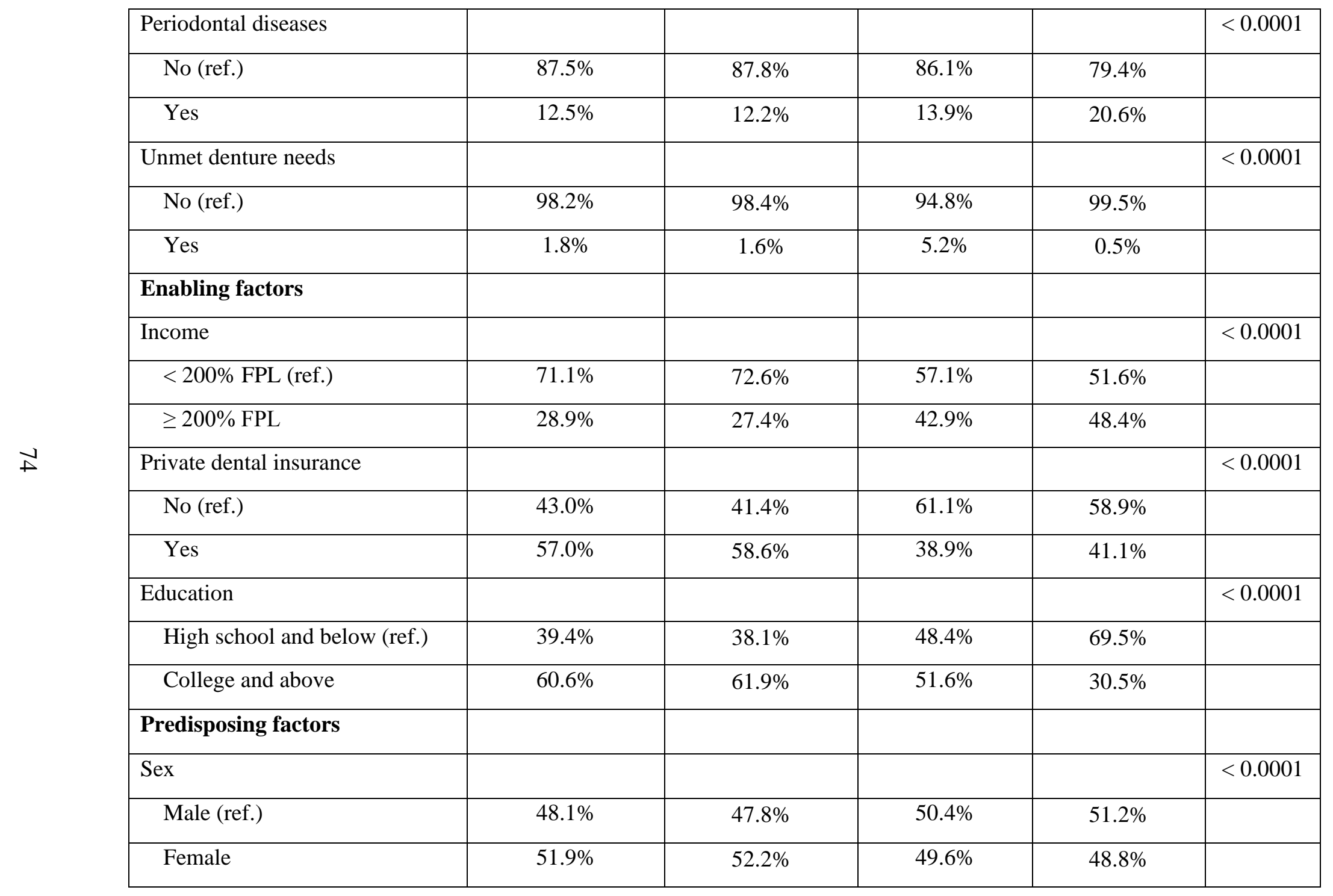




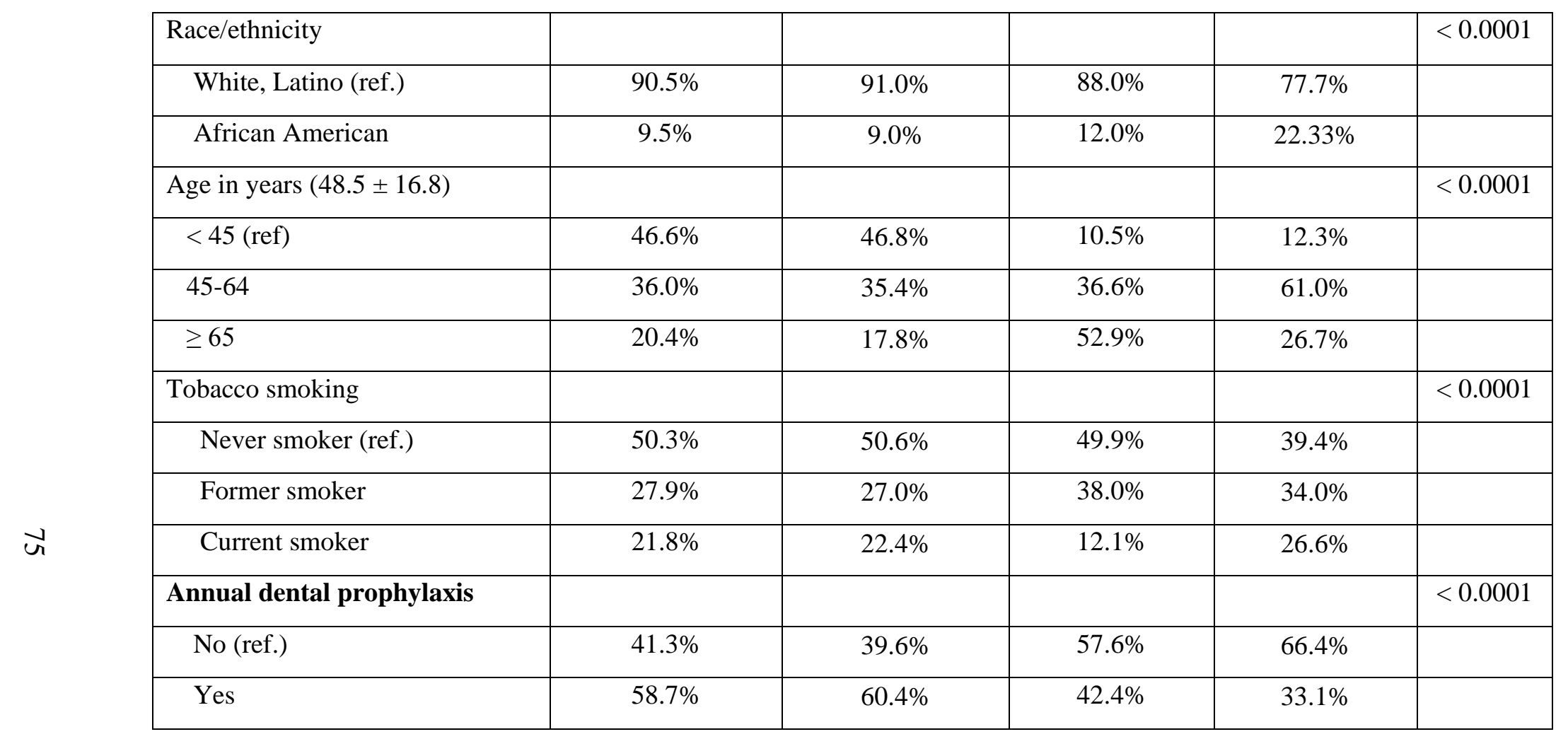


Table 3.3. Distribution of prevalence by item in the weighted sample

\begin{tabular}{|c|c|c|c|c|c|c|}
\hline \multirow{3}{*}{ Item } & \multirow{3}{*}{ Questionnaire } & \multirow{3}{*}{$\begin{array}{c}\text { Total } \\
\text { prevalence }\end{array}$} & \multicolumn{3}{|c|}{ T2DM } & \multirow{3}{*}{$p$ value } \\
\hline & & & \multirow{2}{*}{ No } & \multicolumn{2}{|c|}{ Yes } & \\
\hline & & & & Controlled & Uncontrolled & \\
\hline OHQ.620 & How often last year had aching in mouth? & $5.8 \%$ & $5.49 \%$ & $8.03 \%$ & $11.51 \%$ & $<0.0001$ \\
\hline OHQ.630 & How often felt bad because of mouth’s condition? & $4.0 \%$ & $3.69 \%$ & $6.25 \%$ & $9.74 \%$ & $<0.0001$ \\
\hline OHQ.640 & $\begin{array}{l}\text { Last year had difficulty with job because of mouth's } \\
\text { condition? }\end{array}$ & $1.0 \%$ & $1.03 \%$ & $0.96 \%$ & $0 \%$ & $<0.0001$ \\
\hline OHQ.650 & Last year taste affected because of mouth’s condition? & $1.5 \%$ & $1.34 \%$ & $3.69 \%$ & $3.41 \%$ & $<0.0001$ \\
\hline OHQ.660 & Last year avoid some food because of mouth’s condition? & $5.7 \%$ & $5.79 \%$ & $4.53 \%$ & $3.76 \%$ & $<0.0001$ \\
\hline OHQ.670 & Last year could not eat because of mouth's condition? & $5.2 \%$ & $5.04 \%$ & $6.52 \%$ & $5.93 \%$ & $<0.0001$ \\
\hline OHQ.680 & Last year embarrassed because of mouth's condition? & $5.5 \%$ & $4.91 \%$ & $8.26 \%$ & $23.83 \%$ & $<0.0001$ \\
\hline
\end{tabular}


Table 3.4. Distribution of OHIP scores by domains in the weighted sample

\begin{tabular}{|l|c|c|c|c|c|}
\hline \multirow{2}{*}{ Domain (Items) } & \multirow{2}{*}{ Mean (SE) } & \multicolumn{3}{c|}{ T2DM } & \multirow{2}{*}{$p$ value } \\
\cline { 4 - 6 } & & No & \multicolumn{2}{c|}{ Yes } & \\
\cline { 4 - 6 } & & & Controlled & Uncontrolled & \\
\hline Physiological (OHQ:620, 630, 650, 660, 670) & $2.14(0.07)$ & $2.09(0.07)$ & $2.50(0.32)$ & $3.10(0.49)$ & 0.023 \\
\hline Psychological (OHQ: 680) & $0.40(0.02)$ & $0.37(0.03)$ & $0.58(0.07)$ & $0.95(0.19)$ & 0.004 \\
\hline Social (OHQ: 640) & $0.11(0.01)$ & $0.11(0.01)$ & $0.12(0.04)$ & $0.15(0.06)$ & 0.438 \\
\hline
\end{tabular}

$\mathrm{SE}=$ Standard error 
Table 3.5. Multivariate analysis of factors associated with poor OHRQoL (measured by OHIP-ADD and OHIP-SC)

\begin{tabular}{|c|c|c|c|c|c|c|c|c|}
\hline & \multicolumn{4}{|c|}{$\begin{array}{l}\text { Severity scores } \\
\text { (OHIP-ADD) }\end{array}$} & \multicolumn{4}{|c|}{$\begin{array}{l}\text { Prevalence } \\
\text { (OHIP-SC) }\end{array}$} \\
\hline & \multicolumn{2}{|c|}{ Odds Ratio } & \multicolumn{2}{|c|}{ Marginal Effect } & \multicolumn{2}{|c|}{ Odds Ratio } & \multicolumn{2}{|c|}{ Marginal Effect } \\
\hline & $\mathbf{O R}^{\mathrm{a}}$ & $95 \% \mathrm{CI}$ & $\mathrm{d} y / \mathrm{d} x^{\mathrm{b}}$ & $\mathrm{SE}^{\mathrm{c}}$ & $\mathbf{O R}^{\mathbf{a}}$ & $95 \% \mathrm{CI}$ & $\mathrm{d} y / \mathrm{d} x^{\mathrm{b}}$ & $\mathrm{SE}^{\mathrm{c}}$ \\
\hline \multicolumn{9}{|l|}{ Need factors } \\
\hline \multicolumn{9}{|l|}{ T2DM } \\
\hline No & 1.000 & Reference & \multicolumn{2}{|c|}{ Reference } & 1.000 & Reference & \multicolumn{2}{|c|}{ Reference } \\
\hline Yes with HbA1c < 8\% & 1.332 & $1.330-1.335$ & 0.0410 & 0.000144 & 1.426 & $1.424-1.429$ & 0.0433 & 0.000133 \\
\hline Yes with $\mathrm{HbA} 1 \mathrm{c} \geq 8 \%$ & 1.388 & $1.383-1.392$ & 0.0474 & 0.000243 & 1.730 & $1.725-1.735$ & 0.0716 & 0.000236 \\
\hline \multicolumn{9}{|l|}{ Obesity } \\
\hline $\mathrm{BMI}<30$ kg/m2 & 1.000 & Reference & \multicolumn{2}{|c|}{ Reference } & 1.00 & Reference & \multicolumn{2}{|c|}{ Reference } \\
\hline $\mathrm{BMI} \geq 30 \mathrm{~kg} / \mathrm{m} 2$ & 1.105 & $1.104-1.106$ & 0.0133 & 0.000070 & 1.243 & $1.242-1.244$ & 0.0246 & 0.000064 \\
\hline \multicolumn{9}{|l|}{ Untreated dental caries } \\
\hline No & 1.000 & Reference & \multicolumn{2}{|c|}{ Reference } & 1.000 & Reference & \multicolumn{2}{|c|}{ Reference } \\
\hline Yes & 1.583 & $1.581-1.585$ & 0.0658 & 0.000085 & 1.787 & $1.785-1.789$ & 0.0714 & 0.000079 \\
\hline \multicolumn{9}{|l|}{ Periodontal diseases } \\
\hline No & 1.000 & Reference & \multicolumn{2}{|c|}{ Reference } & 1.000 & Reference & \multicolumn{2}{|c|}{ Reference } \\
\hline Yes & 1.073 & $1.071-1.074$ & 0.0094 & 0.000096 & 1.003 & $1.002-1.004$ & 0.0003 & 0.000083 \\
\hline \multicolumn{9}{|l|}{ Unmet denture need } \\
\hline No & 1.000 & Reference & \multicolumn{2}{|c|}{ Reference } & 1.00 & Reference & & \\
\hline Yes & 1.487 & $1.483-1.492$ & 0.0595 & 0.000269 & 1.715 & $1.710-1.721$ & 0.0715 & 0.000258 \\
\hline \multicolumn{9}{|l|}{ Enabling factors } \\
\hline \multicolumn{9}{|l|}{ Income } \\
\hline$<200 \%$ FPL & 1.000 & Reference & \multicolumn{2}{|c|}{ Reference } & 1.00 & Reference & \multicolumn{2}{|c|}{ Reference } \\
\hline
\end{tabular}




\begin{tabular}{|c|c|c|c|c|c|c|c|c|}
\hline$\geq 200 \% \mathrm{FPL}$ & 1.273 & $1.272-1.275$ & 0.0330 & 0.000079 & 1.220 & $1.219-1.222$ & 0.0225 & 0.000071 \\
\hline \multicolumn{9}{|l|}{ Private dental insurance } \\
\hline No & 1.000 & Reference & & & 1.000 & Reference & \multicolumn{2}{|c|}{ Reference } \\
\hline Yes & 0.874 & $0.874-0.875$ & -0.0178 & 0.000071 & 0.806 & $0.805-0.807$ & -0.0239 & 0.000064 \\
\hline \multicolumn{9}{|l|}{ Education } \\
\hline High school and below & 1.000 & Reference & & & 1.00 & Reference & \multicolumn{2}{|c|}{ Reference } \\
\hline College and above & 0.961 & $0.960-0.962$ & -0.0053 & 0.000070 & 0.848 & $0.847-0.849$ & -0.0183 & 0.000063 \\
\hline \multicolumn{9}{|l|}{ Predisposing factors } \\
\hline \multicolumn{9}{|l|}{ Sex } \\
\hline Male & 1.000 & Reference & \multicolumn{2}{|c|}{ Reference } & 1.000 & Reference & \multicolumn{2}{|c|}{ Reference } \\
\hline Female & 1.311 & $1.310-1.312$ & 0.0356 & 0.000064 & 1.655 & $1.653-1.657$ & 0.0551 & 0.000058 \\
\hline \multicolumn{9}{|l|}{ Race/ethnicity } \\
\hline White, Latino & 1.000 & Reference & \multicolumn{2}{|c|}{ Reference } & 1.000 & Reference & \multicolumn{2}{|c|}{ Reference } \\
\hline African American & 1.199 & $1.198-1.201$ & 0.0252 & 0.000112 & 1.187 & $1.185-1.189$ & 0.0198 & 0.000100 \\
\hline \multicolumn{9}{|l|}{ Age in years $(48.5 \pm 16.8)$} \\
\hline$<45$ & 1.000 & Reference & \multicolumn{2}{|c|}{ Reference } & 1.000 & Reference & \multicolumn{2}{|c|}{ Reference } \\
\hline $45-64$ & 1.181 & $1.180-1.182$ & 0.0230 & 0.000077 & 1.381 & $1.379-1.382$ & 0.0376 & 0.000070 \\
\hline$\geq 65$ & 0.807 & $0.806-0.808$ & -0.0260 & 0.000092 & 0.839 & $0.837-0.840$ & -0.0169 & 0.000080 \\
\hline \multicolumn{9}{|l|}{ Tobacco smoking } \\
\hline Never smoker & 1.000 & Reference & \multicolumn{2}{|c|}{ Reference } & 1.000 & Reference & \multicolumn{2}{|c|}{ Reference } \\
\hline Former smoker & 1.244 & $1.242-1.245$ & 0.0269 & 0.000076 & 1.041 & $1.040-1.043$ & 0.0040 & 0.000066 \\
\hline Current smoker & 1.944 & $1.942-1.946$ & 0.0958 & 0.000092 & 1.993 & $1.990-1.995$ & 0.0868 & 0.000086 \\
\hline \multicolumn{9}{|l|}{ Annual dental prophylaxis } \\
\hline No & 1.000 & Reference & \multicolumn{2}{|c|}{ Reference } & 1.000 & Reference & \multicolumn{2}{|c|}{ Reference } \\
\hline Yes & 0.830 & $0.829-0.831$ & -0.0249 & 0.000070 & 0.834 & $0.833-0.835$ & -0.0202 & 0.000063 \\
\hline
\end{tabular}


Table 4.1. Characteristics of study variables in the weighted sample

\begin{tabular}{|c|c|c|c|c|c|}
\hline \multirow{5}{*}{ Variable } & \multirow{3}{*}{ Total } & \multicolumn{3}{|c|}{ T2DM } & \multirow{5}{*}{$p$ value } \\
\hline & & \multirow{2}{*}{ No } & \multicolumn{2}{|c|}{ Yes } & \\
\hline & & & Controlled & Uncontrolled & \\
\hline & $\mathrm{N}=124,525,899$ & $\mathrm{~N}=113,920,136$ & $\mathrm{~N}=8,296,968$ & $\mathrm{~N}=2,308,795$ & \\
\hline & $(100 \%)$ & $(91.5 \%)$ & $(6.7 \%)$ & $(1.9 \%)$ & \\
\hline Income & & & & & $<0.001$ \\
\hline$>400 \%$ FPL (ref.) & $38.9 \%$ & $40.3 \%$ & $22.7 \%$ & $28.0 \%$ & \\
\hline 200-400 FPL & $32.6 \%$ & $32.6 \%$ & $34.6 \%$ & $23.5 \%$ & \\
\hline$<200 \%$ FPL & $28.5 \%$ & $27.1 \%$ & $42.7 \%$ & $48.5 \%$ & \\
\hline Education & & & & & $<0.001$ \\
\hline Bachelor's or above (ref.) & $28.6 \%$ & $29.3 \%$ & $22.9 \%$ & $10.8 \%$ & \\
\hline Associate degree & $32.3 \%$ & $32.6 \%$ & $31.1 \%$ & $22.0 \%$ & \\
\hline High school diploma & $26.3 \%$ & $26.5 \%$ & $22.5 \%$ & $27.1 \%$ & \\
\hline $9-11^{\text {th }}$ grade & $7.9 \%$ & $7.3 \%$ & $10.3 \%$ & $29.5 \%$ & \\
\hline Less than $9^{\text {th }}$ grade & $4.9 \%$ & $4.2 \%$ & $13.2 \%$ & $10.6 \%$ & \\
\hline Need & & & & & \\
\hline Perceived need & & & & & $<0.001$ \\
\hline No need (ref.) & $38.6 \%$ & $38.7 \%$ & $35.3 \%$ & $43.1 \%$ & \\
\hline 1 treatment & $36.5 \%$ & $36.8 \%$ & $37.8 \%$ & $19.7 \%$ & \\
\hline
\end{tabular}




\begin{tabular}{|c|c|c|c|c|c|}
\hline 2 treatments & $19.9 \%$ & $20.1 \%$ & $19.0 \%$ & $8.7 \%$ & \\
\hline 3 treatments & $5.0 \%$ & $4.4 \%$ & $7.8 \%$ & $28.4 \%$ & \\
\hline Evaluated need & & & & & $<0.001$ \\
\hline No need (ref.) & $68.2 \%$ & $68.5 \%$ & $67.0 \%$ & $59.7 \%$ & \\
\hline 1 treatment & $25.8 \%$ & $25.7 \%$ & $25.7 \%$ & $30.9 \%$ & \\
\hline 2 treatments & $5.9 \%$ & $5.7 \%$ & $7.3 \%$ & $9.4 \%$ & \\
\hline 3 treatments & $0.1 \%$ & $0.1 \%$ & $0 \%$ & $0 \%$ & \\
\hline General health conditions & & & & & $<0.001$ \\
\hline Excellent (ref.) & $13.5 \%$ & $14.5 \%$ & $2.1 \%$ & $5.5 \%$ & \\
\hline Very good & $37.4 \%$ & $39.1 \%$ & $21.1 \%$ & $11.4 \%$ & \\
\hline Good & $33.9 \%$ & $33.3 \%$ & $40.9 \%$ & $38.9 \%$ & \\
\hline Fair or Poor & $15.2 \%$ & $13.1 \%$ & $35.9 \%$ & $44.2 \%$ & \\
\hline \multicolumn{6}{|l|}{ Use } \\
\hline Reason & & & & & $<0.001$ \\
\hline Self-come check-up (ref.) & $46.5 \%$ & $48.2 \%$ & $29.6 \%$ & $19.1 \%$ & \\
\hline Called to check-up & $10.8 \%$ & $10.9 \%$ & $9.3 \%$ & $10.8 \%$ & \\
\hline Bother or hurting & $28.2 \%$ & $27.3 \%$ & $37.9 \%$ & $39.6 \%$ & \\
\hline Treatment & $8.3 \%$ & $7.9 \%$ & $9.8 \%$ & $21.4 \%$ & \\
\hline Other & $6.2 \%$ & $5.7 \%$ & $13.3 \%$ & $9.2 \%$ & \\
\hline
\end{tabular}




\begin{tabular}{|c|c|c|c|c|c|}
\hline Frequency & & & & & $<0.001$ \\
\hline$\leq 6$ months (ref.) & $49.2 \%$ & $50.5 \%$ & $35.9 \%$ & $31.1 \%$ & \\
\hline$\leq 1$ year & $16.6 \%$ & $16.8 \%$ & $16.0 \%$ & $12.1 \%$ & \\
\hline$\leq 2$ years & $10.8 \%$ & $11.1 \%$ & $7.8 \%$ & $9.0 \%$ & \\
\hline$\leq 3$ years & $5.8 \%$ & $5.7 \%$ & $6.1 \% \%$ & $9.1 \%$ & \\
\hline$\leq 5$ years & $5.8 \%$ & $5.7 \%$ & $8.0 \%$ & $2.7 \%$ & \\
\hline$>5$ years or never & $11.8 \%$ & $10.3 \%$ & $26.1 \%$ & $36.0 \%$ & \\
\hline Smoking & & & & & $<0.001$ \\
\hline Never smoke (ref.) & $50.2 \%$ & $50.4 \%$ & $50.5 \%$ & $41.1 \%$ & \\
\hline Former smoker & $28.2 \%$ & $27.3 \%$ & $37.7 \%$ & $36.1 \%$ & \\
\hline Current smoker & $21.6 \%$ & $22.3 \%$ & $11.8 \%$ & $22.4 \%$ & \\
\hline \multicolumn{6}{|l|}{ OHRQoL } \\
\hline OHIP - Physical & $7.11( \pm 3.27)$ & $7.06( \pm 3.19)$ & $7.44( \pm 3.76)$ & $8.23( \pm 4.52)$ & $<0.001$ \\
\hline OHIP - Psychological & $1.39( \pm 0.95)$ & $1.37( \pm 0.90)$ & $1.56( \pm 1.15)$ & $2.04( \pm 1.70)$ & $<0.001$ \\
\hline OHIP - Social & $1.11( \pm 0.47)$ & $1.11( \pm 0.46)$ & $1.13( \pm 0.51)$ & $1.11( \pm 0.47)$ & $<0.001$ \\
\hline
\end{tabular}

ref. = reference category 
Table 4. 2. Fit indices for the measurement (CFA) and SEM models

\begin{tabular}{|c|c|c|c|c|c|c|c|c|c|c|}
\hline \multirow{2}{*}{ Model } & \multicolumn{5}{|c|}{ Absolute indices } & \multicolumn{4}{|c|}{ Relative indices } & \multirow{2}{*}{$\begin{array}{c}\text { Criteria } \\
\text { fitted }\end{array}$} \\
\cline { 2 - 10 } & $\chi^{2} /$ d.f. & $p$ & RMSEA (95\% CI) & SRMR & GFI & NFI & IFI & CFI & TLI & \\
\hline 4.1 & 5.582 & 0.000 & $\mathbf{0 . 0 4 0}(\mathbf{0 . 0 3 4}-\mathbf{0 . 0 4 7})$ & $\mathbf{0 . 0 6 0}$ & $\mathbf{0 . 9 9 9}$ & $\mathbf{0 . 9 4 9}$ & $\mathbf{0 . 9 5 8}$ & $\mathbf{0 . 9 5 8}$ & $\mathbf{0 . 9 3 6}$ & 7 \\
\hline 4.2 & $\mathbf{1 . 7 4 3}$ & 0.001 & $\mathbf{0 . 0 1 7}(\mathbf{0 . 0 1 1}-\mathbf{0 . 0 2 2})$ & 0.099 & $\mathbf{1 . 0 0 0}$ & $\mathbf{0 . 9 3 2}$ & $\mathbf{0 . 9 6 9}$ & $\mathbf{0 . 9 6 8}$ & $\mathbf{0 . 9 5 9}$ & 7 \\
\hline
\end{tabular}

Figures in bold are those in line with the model-fitting criteria.

Model $4.1=$ measurement model; Model $4.2=$ structural model; $\chi^{2}=$ chi-square; d.f. $=$ degrees of

freedom; RSMEA = root-mean-square error of approximation; SRMR = standardized root mean square

residual; GFI = Goodness of Fit Index; NFI = Normed Fit Index NFI, IFI = Incremental Fit Index (IFI);

CFI = comparative fit index; TLI = Tucker-Lewis Index. 
Table 4.3. Factor loadings and correlation coefficients in CFA

\begin{tabular}{|c|c|c|c|c|}
\hline \multirow[b]{2}{*}{ Factor loadings of measured indicators } & \multicolumn{3}{|c|}{$\lambda$} & \multirow[b]{2}{*}{$p$} \\
\hline & Need & $\begin{array}{l}\text { Use and } \\
\text { behavior }\end{array}$ & OHRQoL & \\
\hline Perceived treatment need & 0.59 & & & $<0.001$ \\
\hline Evaluated treatment need & 0.40 & & & $<0.001$ \\
\hline General health conditions & 0.45 & & & $<0.001$ \\
\hline Reason for dental visits & & 0.70 & & $<0.001$ \\
\hline Frequency of dental visit & & 0.40 & & $<0.001$ \\
\hline Smoking status & & 0.36 & & $<0.001$ \\
\hline OHIP - Physical & & & 0.75 & $<0.001$ \\
\hline OHIP - Psychological & & & 0.68 & $<0.001$ \\
\hline OHIP - Social & & & 0.67 & $<0.001$ \\
\hline Correlations between latent variables & & $\theta$ & & $p$ \\
\hline Need $\leftrightarrow$ Use and behavior & & 0.78 & & $<0.001$ \\
\hline Need $\leftrightarrow$ OHRQoL & & 0.30 & & $<0.001$ \\
\hline OHRQoL $\leftrightarrow$ Use and behavior & & 0.61 & & $<0.001$ \\
\hline
\end{tabular}

$\lambda=$ Factor loadings

$\theta=$ Correlation coefficients 
Table 4.4. Path coefficients in SEM

\begin{tabular}{|c|c|c|c|c|}
\hline \multirow[b]{2}{*}{ Path coefficients of measured indicators } & \multicolumn{3}{|c|}{$\delta$} & \multirow[b]{2}{*}{$p$} \\
\hline & Need & $\begin{array}{l}\text { Use and } \\
\text { behavior }\end{array}$ & OHRQoL & \\
\hline Perceived treatment need & 0.90 & & & $<0.001$ \\
\hline Evaluated treatment need & 0.59 & & & $<0.001$ \\
\hline General health conditions & 0.57 & & & $<0.001$ \\
\hline Reason for dental visits & & 0.70 & & $<0.001$ \\
\hline Frequency of dental visit & & 0.37 & & $<0.001$ \\
\hline Smoking status & & 0.37 & & $<0.001$ \\
\hline OHIP - Physical & & & 0.75 & $<0.001$ \\
\hline OHIP - Psychological & & & 0.69 & $<0.001$ \\
\hline OHIP - Social & & & 0.68 & $<0.001$ \\
\hline
\end{tabular}


Table 4.5. Effect coefficients in SEM

\begin{tabular}{|c|c|c|}
\hline Direct effects & $\boldsymbol{\beta}$ & $\boldsymbol{p}$ \\
\hline Diabetes $\rightarrow$ Need & 0.49 & $<0.05$ \\
\hline Education $\rightarrow$ Use and behavior & 0.37 & $<0.001$ \\
\hline Income $\rightarrow$ Use and behavior & 0.32 & $<0.01$ \\
\hline Need $\rightarrow$ Use and behavior & 0.46 & $<0.001$ \\
\hline Use and behavior $\rightarrow$ OHRQoL & 0.19 & $<0.001$ \\
\hline Need $\rightarrow$ OHRQoL & 0.30 & $<0.001$ \\
\hline Indirect effects & $\boldsymbol{\alpha}$ & $\boldsymbol{p}$ \\
\hline Need $\rightarrow$ OHRQoL & 0.09 & $<0.001$ \\
\hline Total effects & $\boldsymbol{\omega}$ & $<0.001$ \\
\hline Need $\rightarrow$ OHRQoL & 0.39 & \\
\hline$\beta=$ Direct effect coefficients \\
$\alpha=$ Indirect effect coefficients \\
$\omega=$ Total effect coefficients & & \\
\hline
\end{tabular}


Figure 1.1. Andersen’s Behavioral Model of Health Care Utilization

\section{ENVIRONMENT POPULATION CHARACTERISTICS $\begin{aligned} & \text { HEALTH } \\ & \text { BEHAVIOR }\end{aligned}$}

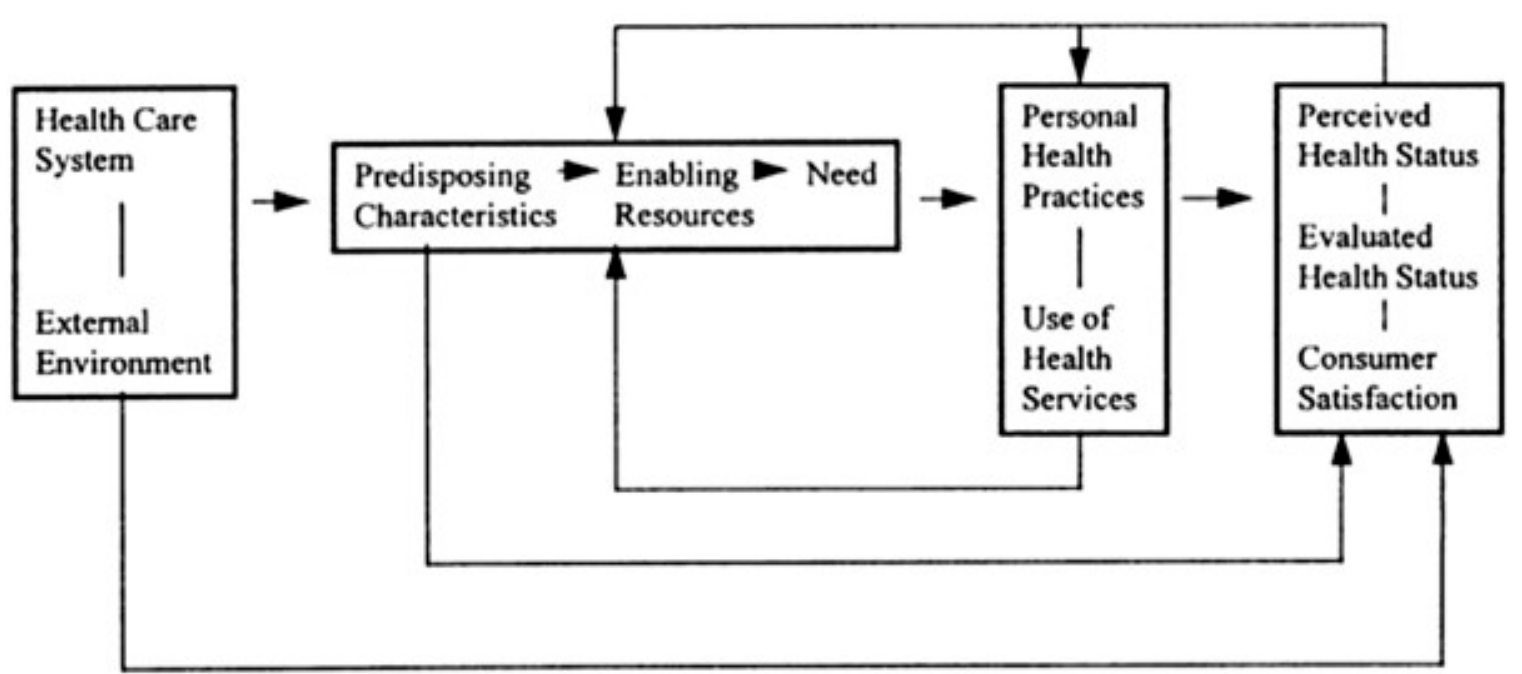


Figure 2.1. PRISMA flow diagram illustrating the study selection process

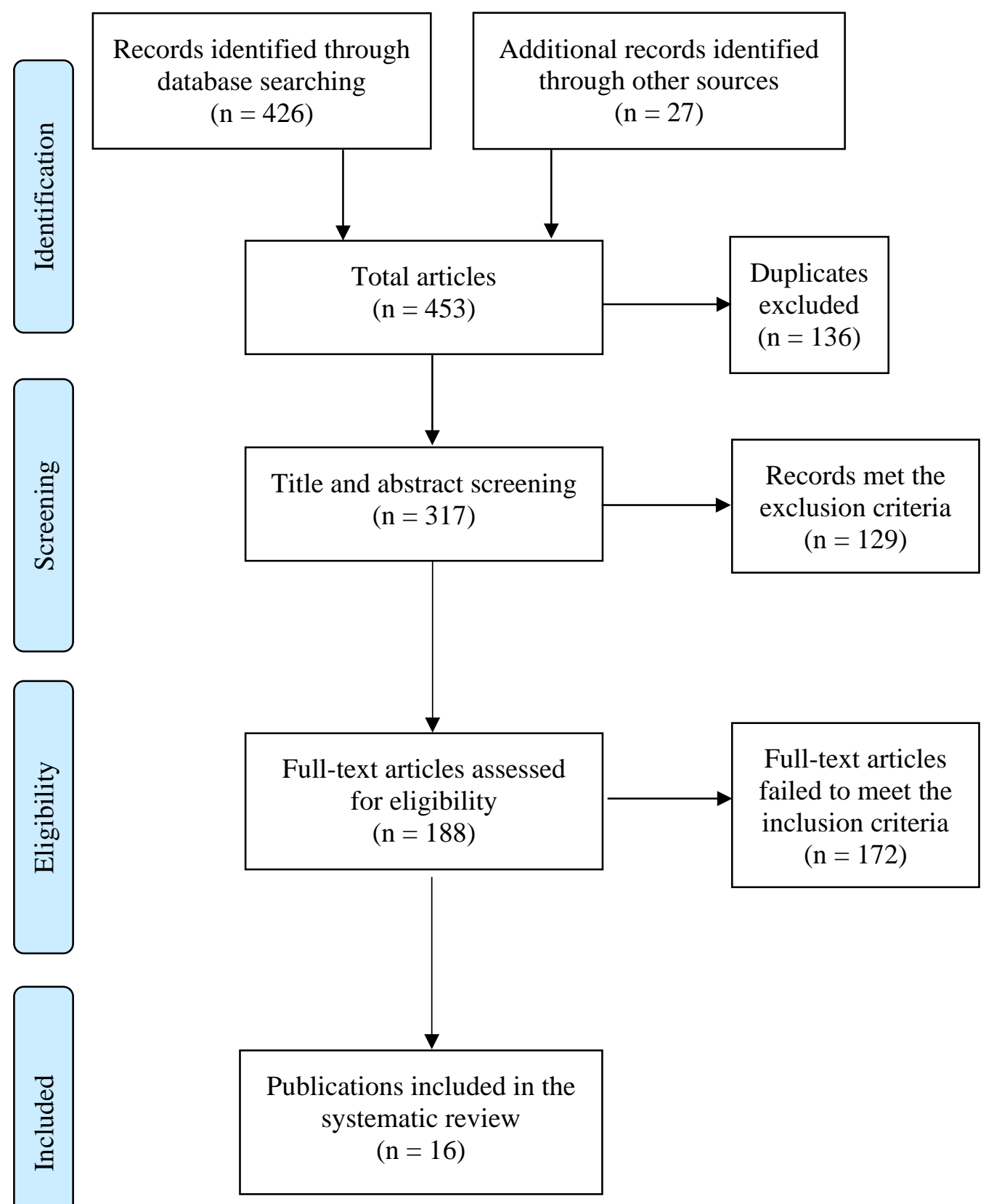


Figure 3.1. Pathways of factors in Andersen model

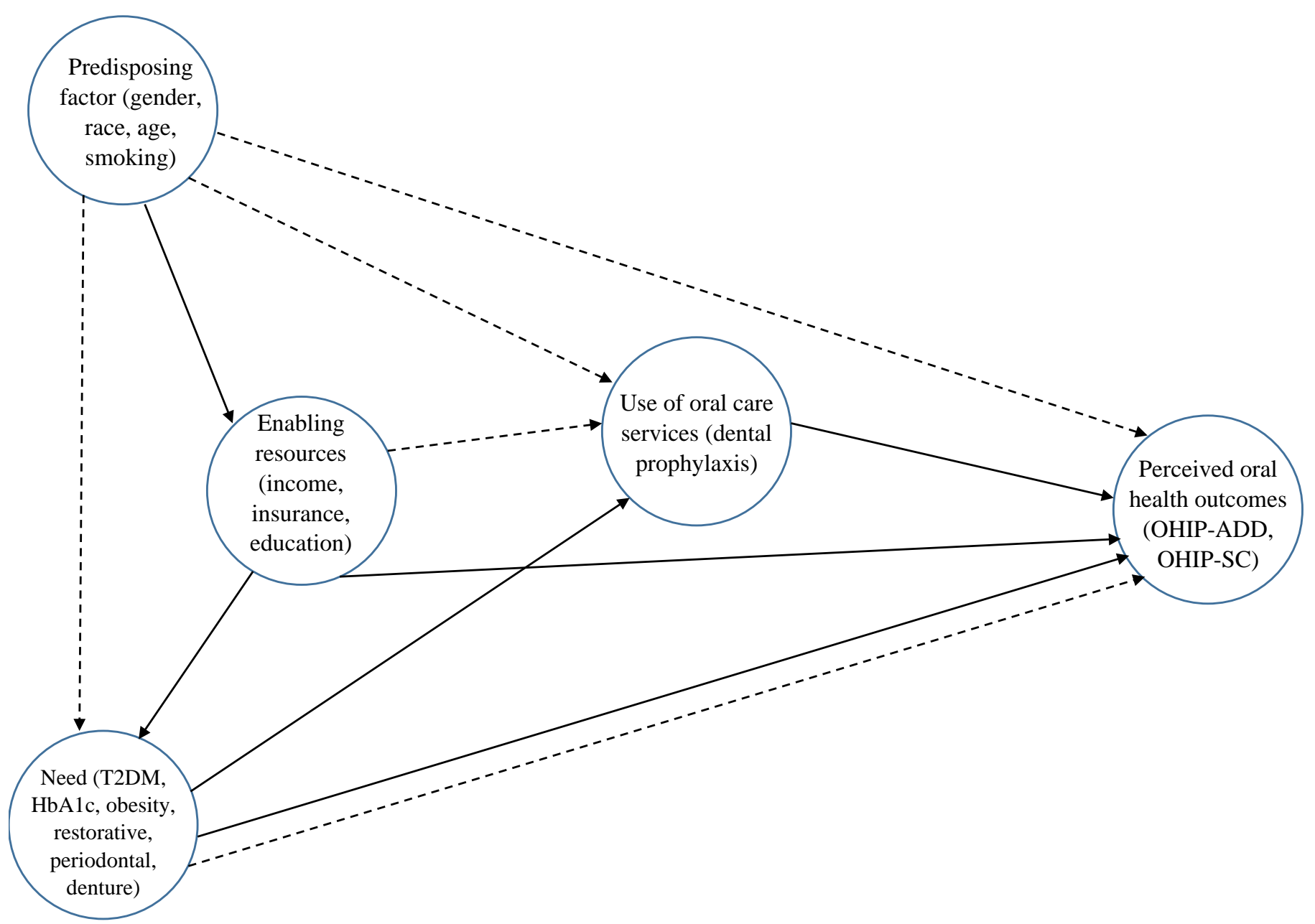


Figure 4.1. DWLS standardized estimates for the confirmatory factor analysis.

$$
\begin{aligned}
* \mathrm{p} & <0.05 ;{ }^{* *} \mathrm{p}<0.01 ; * * * \mathrm{p}<0.001 \\
\lambda & =\text { Factor loadings } \\
\theta & =\text { Correlation coefficients } \\
\delta & =\text { Path coefficients } \\
\beta & =\text { Direct effect coefficients } \\
\alpha & =\text { Indirect effect coefficients } \\
\omega & =\text { Total effect coefficients } \\
\mathrm{R}^{2} & =\text { Variance } \\
\mathrm{e} & =\text { error term }
\end{aligned}
$$

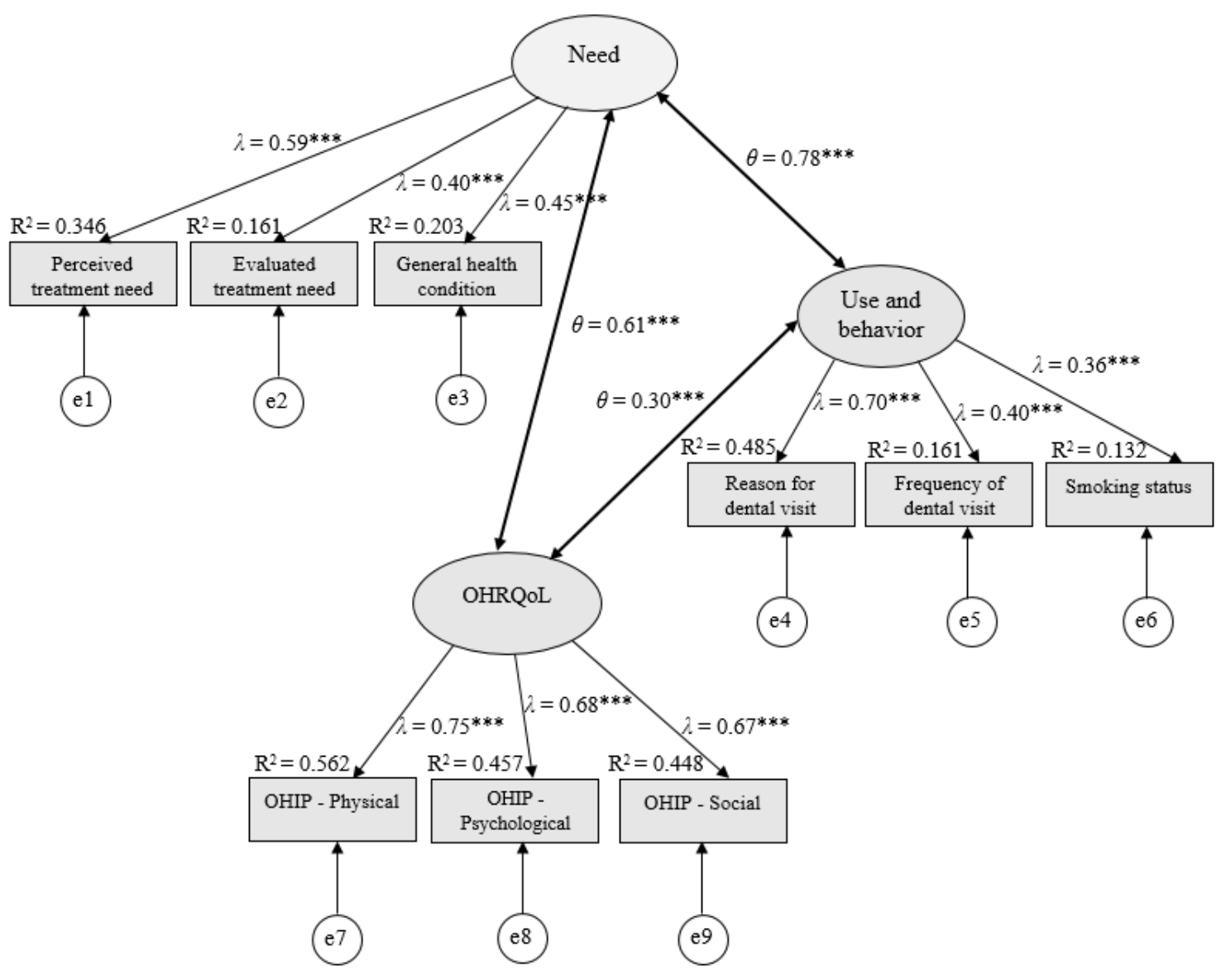


Figure 4.2. DWLS standardized estimates for the structural model.

$$
\begin{aligned}
& *_{\mathrm{p}}<0.05 ;{ }^{* *} \mathrm{p}<0.01 ; * * * \mathrm{p}<0.001 \\
& \lambda=\text { Factor loadings } \\
& \theta=\text { Correlation coefficients } \\
& \delta=\text { Path coefficients } \\
& \beta=\text { Direct effect coefficients } \\
& \alpha=\text { Indirect effect coefficients } \\
& \omega=\text { Total effect coefficients } \\
& \mathrm{R}^{2}=\text { Variance } \\
& \mathrm{e}=\text { error term }
\end{aligned}
$$

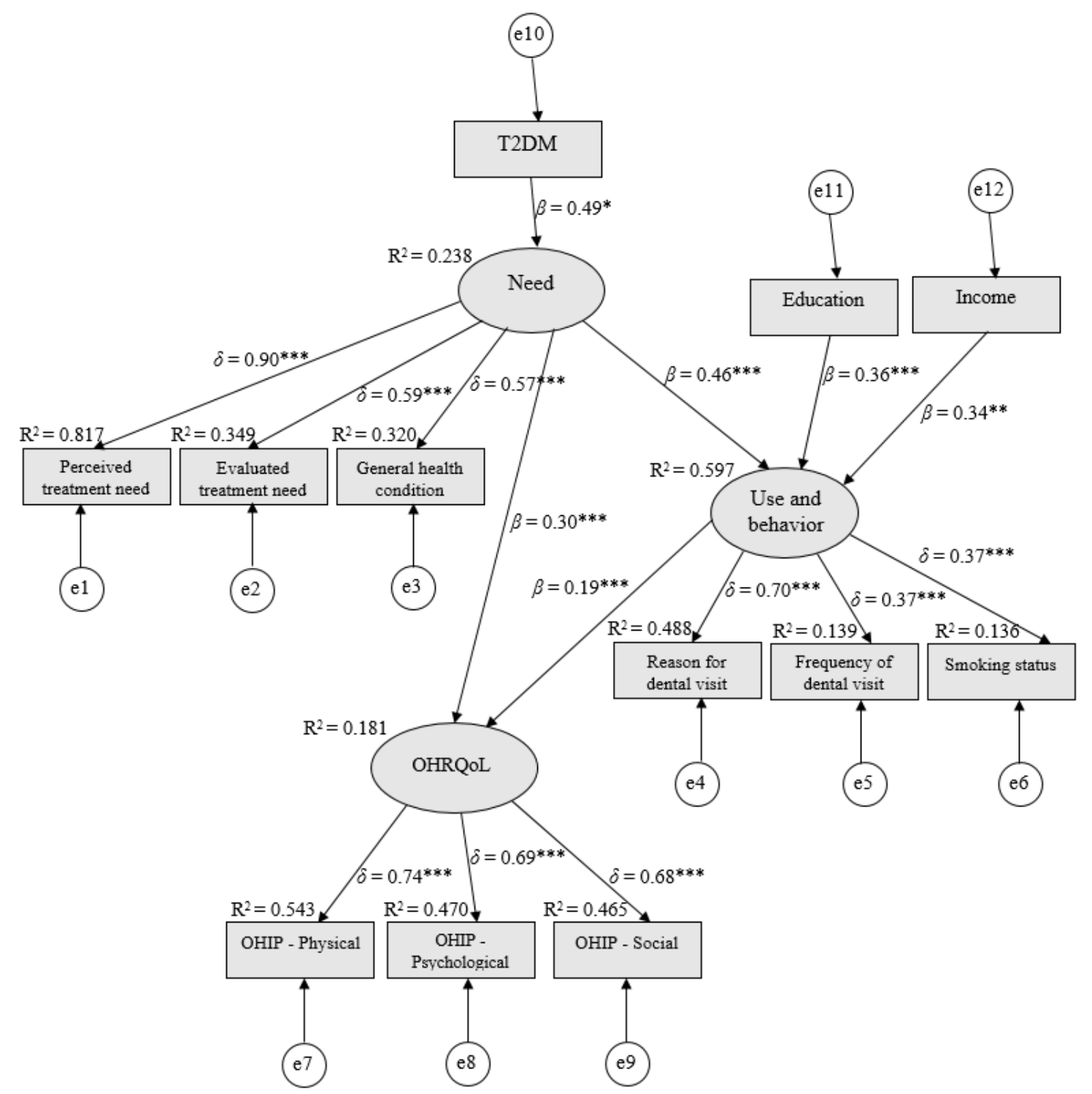




\section{CURRICULUM VITA}

Name: Giang Truong Vu

Address: Department of Health Management and Systems Sciences 485 East Gray Street University of Louisville Louisville, KY 40202

DOB: $\quad$ Sa Dec, Dong Thap, Vietnam - April 10, 1987

\section{Education}

\& Training: $\quad$ Doctor of Dental Surgery (D.D.S.)

Can Tho University of Medicine and Pharmacy 2005-2011

A.S., Physics

Georgia State University

2012-2015

M.S., Health Care Management

University of Rochester

2015-2016

Ph.D., Public Health Sciences - Health Management and Policy University of Louisville 2016-2020

Awards: Merit-based Scholarships

Can Tho University of Medicine and Pharmacy

2005-2011

Dean's List Student

Georgia State University

2013-2014

Highest Honors

Georgia State University

2015

Merit-based Scholarships

University of Rochester

2015-2016 


\section{Employments: Dentist}

Nhu Ngoc Dental, Can Tho, Vietnam

$2010-2011$

Dental Office Manager

Southeast Dental, Atlanta, GA

$2011-2015$

Dental Assistant

ODA Primary Health Care Network, New York, NY

$2015-2016$

Graduate Research Assistant

Health Management and Systems Sciences

School of Public Health and Information Sciences

University of Louisville, Louisville, KY

2016 - Present

Instructor

Health Management and Systems Sciences

School of Public Health and Information Sciences

University of Louisville, Louisville, KY

2018 - Present

\section{Professional Societies}

Member

American Association of Public Health Dentistry

2016 - Present

Founding Chapter President

American Association of Public Health Dentistry - University of Louisville Chapter, Louisville, KY

2017 - Present

Member

American Association of Public Health

2016 - Present

\section{Publications/Presentations:}

\section{Dental Research:}

a. Haldankar, M., Vu, G., Gettleman, L., \& Little, B. B. (2018). Oral Health Disparities in LGB Populations. 2018. Research!Louisville. 
b. Vu, G., Little, B. B., Esterhay, B., Jenning J., Creel, L., Gettleman, L. Factor associated with oral health-related quality of life in adults with type 2 diabetes mellitus: A systematic literature review. (Working paper - First dissertation paper)

c. Vu, G., Little, B. B., Esterhay, B., Jenning J., Creel, L., Gettleman, L. Oral health-related quality of life in US adults with type 2 diabetes. (Second dissertation paper, submitted to Community Dentistry and Oral Epidemiology in October 2019 and under review)

d. Vu, G., Little, B. B., Esterhay, B., Jenning J., Creel, L., Gettleman, L. Links between oral health-related quality of life in US adults and type 2 diabetes: Structural equation modeling analysis. (Working paper - Third dissertation paper)

e. Vu, G., Little, B. B., Esterhay, B., Jenning J., Creel, L., Gettleman, L. The association of dental insurance coverage with oral health outcomes and dental care utilization among diabetic patients older than 65 years old. (Working paper)

\section{Type 2 Diabetes Mellitus (T2D) Research:}

a. Tangelloju, S., Vu, G., Chavis-Blakely, H., \& Little, B. B. (2018). Type 2 Diabetes Remission-Analysis of Three Population-Level Historical Cohorts. 2018. Diabetes 67(1):1668-P.

\section{Other Research:}

a. Vu, G., Harper, D., \& Little, B. B. (2018). Fractures of the Hip, Wrist and Spine in Post-Menopausal Women in the NHANES DXA Study. 2018.

Research!Louisville.

b. Little BB, Reilly R, Walsh B, Vu GT. 2020. Cadmium is associated with Type 2 Diabetes in a Superfund Site Lead Smelter Community in Dallas, Texas. Diabetes Metabolism, Research and Reviews (in review).

\section{Research Support}

Graduate Research Assistant, 50\% time

University Partnership - Study on Type 2 Diabetes among Medicaid Beneficiaries in Kentucky, Dept. of Medicaid Services. \$431,680, 2018-2020.

2018-2020

\section{Teaching Activities}

Giang Vu has taught and built teaching materials for biomedical foundations, research methods, data mining, data management, and health policy courses for graduate students at University of Louisville.

- PHMS-681 Population Health Research Methods (Fall 2018)

- PHMS-610/710 Health Policy Analysis (Spring 2019)

- PHMS-641 Data Mining I (Fall 2019)

- PHMS-642 Data Mining II (Spring 2020) 